\title{
Revisão taxonômica de Lonchocarpus s. str. (Leguminosae, Papilionoideae) do Brasil
}

Marcos José da Silva ${ }^{1,3}$ e Ana Maria Goulart de Azevedo Tozzi²

Recebido em 21/06/2011. Aceito em 20/02/2012

\section{RESUMO}

(Revisão taxonômica de Lonchocarpus s. str. (Leguminosae, Papilionoideae) do Brasil). É apresentada a revisão das espécies brasileiras de Lonchocarpus s. str., a qual baseou-se em estudos de campo e na análise de aproximadamente 1.200 coleções de herbários. Foram reconhecidas nove espécies: L. cultratus, L. hedyosmus, L. latifolius, L. macrocarpus, L. nitidus, L. pluvialis, L. sericeus, L. spiciflorus e L. violaceus, ocorrendo em formações florestais geralmente associadas às margens de rios. Lonchocarpus sericeus e L. cultratus apresentam distribuição ampla em todo o Brasil, enquanto L. hedyosmus, L. macrocarpus, L. spiciflorus e L. latifolius são restritas ao domínio amazônico. Lonchocarpus pluvialis ocorre nas Regiões Centro-Oeste (Mato Grosso do Sul e Goiás) e Sudeste (São Paulo) e L. violaceus é encontrada nos Estados da Bahia e Espírito Santo, sendo este o seu primeiro registro para o Brasil. São apresentadas chaves de identificação, descrições e ilustrações, informações sobre habitat e distribuição geográfica, além de comentários taxonômicos e nomenclaturais das espécies. São propostas quatro novas sinonimizações e cinco lectotipificações.

Palavras-chave: Fabaceae, lectotipificação, Millettieae, nomenclatura, taxonomia

\begin{abstract}
(Taxonomic revision of Lonchocarpus s. str. (Leguminosae, Papilionoideae) from Brazil). A revision of the Brazilian species of Lonchocarpus s. str. is presented. This study is based on field observation and an analysis of approximately 1,200 herbarium collections. Nine species are recognized, L. cultratus, L. hedyosmus, L. latifolius, L. macrocarpus, $L$. nitidus, L. pluvialis, L. sericeus, L. spiciflorus, and L. violaceus, which grow in forests and are usually associated with river banks. Lonchocarpus sericeus and L. cultratus have a wide distribution throughout Brazil, whereas L. hedyosmus, L. macrocarpus, L. spiciflorus, and L. latifolius are restricted to the Amazonian domain. Lonchocarpus pluvialis occurs in the Central-West (Mato Grosso do Sul and Goiás) and Southeast (São Paulo) regions. Lonchocarpus violaceus is found in the states of Bahia and Espírito Santo, and is reported for the first time for Brazil. Identification keys, descriptions, and illustrations, in addition to information about habitat, geographic distribution and taxonomic and nomenclatural comments, are provided for the species. Four new synonyms and five lectotypifications are proposed.
\end{abstract}

Key words: lectotypification, Fabaceae, Millettieae, nomenclature, taxonomy

\section{Introdução}

Lonchocarpus Kunth s. lat. é o gênero mais diverso da tribo Millettieae na região neotropical. É conhecido pela taxonomia problemática decorrente de suas relações históricas com os gêneros Deguelia Aubl., Derris Lour., Muellera L.f. e Philenoptera Hochst. ex A. Rich. (Geesink 1984; Tozzi 1989). Foi estudado principalmente por Bentham (1860), Pittier (1917), Tozzi (1989) e Sousa (1992, 2005a,b, 2009a,b,c), incluindo entre 120 e 180 espécies (Schrire 2005; Sousa 2005a,b, 2009a).
Filogeneticamente, o gênero mostrou-se parafilético (Hu et al. 2002), abrangendo três clados com morfologia e distribuição geográfica peculiares (Silva 2010). Um destes clados foi reconhecido como Lonchocarpus s. str., tendo como sinapomorfia os pseudorracemos com eixo de $2^{\text {a }}$ ordem formando um "Y" com os pedicelos. Segundo esta circunscrição reduzida, Lonchocarpus (sensu Silva 2010) deve incluir cerca de 120 espécies, aproximadamente 3/4 delas mesoamericanas, não abrangendo Lonchocarpus sect. Laxiflori (Taub.) Benth., que possui pseudorracemos com flores geminadas, mas não pedicelos em "Y" com o eixo de

\footnotetext{
1 Universidade Federal de Goiás, Instituto de Ciências Biológicas, Departamento de Biologia Geral, Campus Samambaia II, 74001-970, Goiânia, GO, Brasil

2 Universidade Estadual de Campinas, Instituto de Biologia, Departamento de Biologia Vegetal, Campinas, SP, Brasil

3 Autor para correspondência: marcos_agrorural@hotmail.com
} 
$2^{\mathrm{a}}$ ordem, nem parte de Lonchocarpus sect. Punctati (Taub.) Benth., que apresenta flores em panículas. O gênero passa a reunir espécies arbóreas ou raramente arbustivas, de folhas alterno-dísticas, raramente espiraladas, com folíolos opostos ou subopostos, pontuados ou não, pseudorracemos axilares ou terminais, com eixo de $2^{\mathrm{a}}$ ordem formando um Y com os pedicelos, androceu pseudomonadelfo, com 10 estames e tubo estaminal com margens calosas na base, gineceu com 1 a 10 óvulos e frutos geralmente indeiscentes (Silva 2010).

Tozzi (1989) registrou 23 espécies de Lonchocarpus (s. lat.) para o Brasil, porém novas ocorrências, novos táxons e novos sinônimos foram apontados para o grupo desde então (e.g., Tozzi 1995; Neubert \& Miotto 1996; Tozzi \& Silva 2007; Silva \& Tozzi 2008, 2010; Silva et al. 2010). Daquelas 23 espécies, 16 não pertencem a Lonchocarpus s. str. (Silva 2010) e devem ser transferidas para Muellera ou Dahlstedtia Malme. Neste trabalho, é apresentada a revisão taxonômica das espécies brasileiras de Lonchocarpus s. str.

\section{Material e métodos}

Este estudo está baseado na análise de aproximadamente 1.200 exsicatas, incluindo todas as coleções-tipo provenientes de herbários nacionais e estrangeiros $(\mathrm{B}, \mathrm{BHCB}, \mathrm{BM}, \mathrm{C}$, CEN, COL, COR, CEPEC, CH, CPAP, CTES, ESA, F, FHO, FR, FLOR, G, GH, HB, HBR, HUEFS, IAC, IAN, IBGE, ICN, IJ, INPA, IPEAN, K, L, LE, M, MBM, MEXU, MG, MO, NY, OXF, P, PEUFR, R, RB, S, SP, SPSF, U, UB, UEC, UFG e US - siglas de acordo com Thiers 2009), além de observações no campo (os exemplares coletados estão depositados no Herbário UEC). As citações das obras seguiram Lawrence et al. (1968) e Stafleu \& Cowan (1976-1988) e as abreviações dos nomes de autores, Brummit \& Powell (1992). Para as descrições das espécies, seguiu-se o procedimento usual em taxonomia, complementado com os dados das etiquetas de herbário. A terminologia utilizada baseou-se em Bentham (1860) e Tozzi (1989) e, quando necessário, foi complementada por Hickey (1973) e Radford et al. (1974). Os dados referentes às estruturas secretoras seguem Teixeira et al. (2000). O tamanho das flores inclui o comprimento do pedicelo, do cálice e do estandarte. O termo legume samaroide é aplicado aos frutos indeiscentes, conspicuamente compressos e leves. As ilustrações, constando de um ramo fértil e dos principais caracteres reprodutivos utilizados na delimitação das espécies, foram feitas em nanquim sobre papel vegetal, com auxílio de câmara clara acoplada a microscópios estereoscópicos Carl Zeiss e Olympus. Informações sobre habitat e tipos vegetacionais onde ocorrem as espécies foram tomadas a partir das fichas de coletas, observações em campo e bibliografia especializada (e.g., Schrire et al. 2005).

\section{Tratamento Taxonômico}

Lonchocarpus Kunth in Humboldt, Bonpland \& Kunth, Nov. Gen. Sp. (fol. ed.) 6: 300. 1824, nom. cons. Espécie- -tipo: L. sericeus (Poir.) Kunth ex DC. (Robinia sericea Poir.), typ. cons.

Árvore; casca acinzentada ou marron, lisa, rugosa ou tuberculada, com ou sem fissuras, lenticelas cremes a esbranquiçadas. Estípulas precocemente caducas. Folhas alternas, dísticas; estipelas ausentes; pulvinos e peciólulos rugosos; pecíolo e raque cilíndricos a angulosos, usualmente canaliculados na face superior, glabros a indumentados; folíolos (5)7-9(13, 15 ou 17), opostos, raramente subopostos ou subalternos, elípticos, oblongos a oblongo-elípticos ou obovais, glabros a velutinos, com ou sem pontuações. Pseudorracemos eretos ou ascendentes, solitários e axilares ou falsamente terminais, e neste caso formando aglomerados nas terminações de ramos desfolhados semelhantes a uma pseudopanícula; eixo de segunda ordem bifloro e formando um Y com os pedicelos florais; brácteas e bractéolas presentes, persistentes ou caducas, com ou sem pontuações; brácteas situadas na base do pseudorracemo (bráctea de $1^{\mathrm{a}}$ ordem), do eixo de segunda ordem $\left(2^{\mathrm{a}}\right)$ e do pedicelo $\left(3^{\mathrm{a}}\right)$, as bracteólas usualmente situadas desde a metade até o ápice do pedicelo. Flores usualmente lilás a purpúreas, raramente esbranquiçadas a vermelhas, mecanismo de abertura explosivo ou valvar; cálice e corola com ou sem pontuações; corola pentâmera, papilionácea; alas usualmente unidas às pétalas da quilha lateralmente; pétalas da quilha unidas entre si; androceu pseudomonadelfo, estames 10, filetes em duas classes de alturas; porção livre dos filetes e anteras usualmente glabras; ovário linear, séssil ou estipitado. Frutos glabros a indumentados, lanceolados a elípticos, margem vexilar nerviforme, alada ou espessada. Sementes usualmente reniformes, planas ou túrgidas, com testa coriácea a papirácea, marrom-escuras a castanho-avermelhadas.

Lonchocarpus s. str. inclui cerca de 120 espécies distribuídas do México até a América do Sul, com apenas uma espécie, $L$. sericeus, ocorrendo também na costa oeste da África. Na América do Sul, está representado por 15-20 espécies dispersas especialmente nas florestas sazonalmente secas ou úmidas da porção setentrional, incluindo a floresta Amazônica e ambientes associados. Das espécies sulamericanas do gênero, nove ocorrem no Brasil (L. cultratus, $L$. hedyosmus, L. latifolius, L. macrocarpus, L. nitidus, L. pluvialis, L. sericeus, L. spiciflorus e L. violaceus) em formações florestais, geralmente associadas às margens de rios, desde o nível do mar até mais de $1.200 \mathrm{~m}$ de altitude. Quatro espécies estão restritas ao domínio amazônico (L. hedyosmus, L. macrocarpus, L. spiciflorus e L. la tifolius), L. sericeus e $L$. cultratus apresentam distribuição ampla em todo o Brasil, L. pluvialis ocorre nas Regiões Centro-Oeste e Sudeste e $L$. violaceus é encontrada nos Estados da Bahia e Espírito Santo.

A maior parte destas espécies (L. hedyosmus, L. latifolius, $L$. macrocarpus, L. nitidus, L. spiciflorus) pertence a Lonchocarpus sect. Densiflori Benth.; L. cultratus, L. pluvialis e L. sericeus pertencem à seção típica e L. violaceus à Lonchocarpus sect. Punctati Benth. Entretanto, essas seções são para- ou polifiléticas, aparecencod em clados morfologicamente distintos (Silva 2010).

Lonchocarpus s. str. relaciona-se morfologicamente com os gêneros Dahlstedtia e Muellera, os quais podem ser identificados pela seguinte chave: 


\section{Chave para identificação de Lonchocarpus s. str. e táxons relacionados}

1. Flores em panículas; porção livre dos filetes e anteras usualmente indumentadas; frutos conspícuamente compressos e alados na margem vexilar

Dahlstedtia

1. Flores em pseudorracemos; porção livre dos filetes e anteras glabras a raramente indumentadas; frutos compressos a túrgidos, margem superior nerviforme, alada ou quilhada.

2. Folíolos não translúcido-punctados; pseudorracemos com flores geminadas inseridas diretamente na raque; corola delicadamente membranácea com face externa glabra a discretamente serícea; estandarte não auriculado e glabro acima da unguícula

Muellera

2. Folíolos translúcido-punctados ou não; pseudorracemos com eixo de $2^{\mathrm{a}}$ ordem formando um Y com os pedicelos florais; corola não delicadamente membranácea e conspicuamente serícea externamente; estandarte usualmente subauriculado e com tricomas acima da unguícula

Lonchocarpus s. str.

\section{Chave para as espécies de Lonchocarpus s. str. ocorrentes no Brasil}

1. Venação dos folíolos eucamptódroma; bractéolas opostas e dispostas comumente entre a metade e o terço superior do pedicelo; frutos papiráceos a ligeiramente cartáceos.

2. Plantas não mimercófilas; ramos cheios em seção transversal.

3. Pseudorracemos lenhosos, $15-22 \mathrm{~cm}$ compr.; flores 19-22 mm compr.

2. L. hedyosmus

3. Pseudorracemos delgados, até $7 \mathrm{~cm}$ compr; flores $12-14,5 \mathrm{~mm}$ compr.

4. L. macrocarpus

2. Plantas mimercófilas; ramos fistulosos em seção transversal.

4. Raque e pecíolo cilíndricos, não alados; ápice dos folíolos curto-acuminado; pseudorracemos com eixos delgados e sem aspecto espiciforme; corola vermelha

3. L. latifolius

4. Raque e pecíolo usualmente angulosos e com margens subaladas; ápice dos folíolos arredondado; pseudorracemos espessados e com aspecto espiciforme conferido pelas folhas adensadas e subsésseis; corola branca a creme. .....

1. Venação dos folíolos broquidódroma com nervuras terciárias oblíquas, raramente subperpendiculares; bractéolas na base do cálice; frutos cartáceos, lenhosos a coriáceos.

5. Folíolos translúcido-punctados; pseudorracemos com eixos de $2^{\mathrm{a}}$ ordem de 6-10 mm compr.; frutos alados na margem vexilar

5. Folíolos não translúcido-punctados; pseudoracemos com eixos de $2^{\mathrm{a}}$ ordem de 1,5-4 mm compr.; frutos com margem vexilar nerviforme ou alargada.

6. Frutos com margem vexilar alargada.

8. Ramos jovens, pecíolo, raque e peciólulo hialinos a ferrugíneo-pubescentes ou glabros; pétalas sem pontuações; frutos com quilhas da margem vexilar discretas (2-2,1 mm larg.), retas e sem região da sutura carpelar exposta

1. L. cultratus

8. Ramos jovens, pecíolo, raque e peciólulo tomentoso-amarelados a ferrugíneos; pétalas com pontuações; frutos com quilhas da margem vexilar conspícuas (4,5-5 mm larg.), encurvadas e exibindo a região da sutura carpelar

6. Frutos com a margem vexilar nerviforme.

6. L. pluvialis

7. Folíolos elípticos, às vezes lanceolados, ovais ou espatulados; flores 13,9-16 mm compr.; cálice truncado; frutos cartáceos, glabrescentes, não constrictos entre as sementes e não se separando em artículos quando maturos

5. L. nitidus

7. Folíolos frequentemente oval-oblongos a elíptico-obovais, raramente elípticos; flores 17-25 mm compr., cálice com 3 lacínios desenvolvidos; frutos coriáceos a lenhosos, velutinos, usualmente constrictos entre as sementes e separando-se em artículos quando maturos 7. L. sericeus

1. Lonchocarpuscultratus (Vell.) A.M.G. Azevedo \& H.C. Lima, Acta Bot. Brasil. 9: 128. 1995. Pterocarpus cultratus Vell., Fl. Flumin.: 301.1829 ('1825'). Tipo: Fl. Flumin. Icon. 7: tab. 95. 1831 ('1827') (Lectótipo, designado por Lima 1995).

Neuroscapha guilleminiana Tul., Ann. Sci. Nat., Bot., sér. 2, 20: 137. 1843. Lonchocarpus neuroscapha var. glabrescens Benth., Fl. Bras. 15(1): 278. 1862. Lonchocarpus guille- minianus (Tul.) Malme, Ark. Bot. 23A(13): 30. 1931. Derris guilleminiana (Tul.) J.F. Macbr., Publ. Field Mus. Nat. Hist., Bot. Ser. 13: 262. 1943. Tipo: Brasil. Rio de Janeiro: Corcovado, 1840, fl., G. Guillemin 241 (Lectótipo: P!, aqui designado; Isolectótipo: $\mathrm{K}$ !).

Neuroscapha pubigera Tul., Ann. Sci. Nat., Bot., sér. 2, 20: 137. 1843. Lonchocarpus neuroscapha var. pubiger (Tul.) 
Benth., Fl. Brasil. 15(1): 278. 1862. Tipo: Brasil. P. Claussen s.n. (Holótipo: P!; Isótipo: LE!). Syn. nov.

Neuroscapha martiana Tul., Ann. Sci. Nat., Bot., sér. 2, 20: 137 1843. Lonchocarpus neuroscapha Benth., J. Linn. Soc. 4 (Suppl.): 89. 1860, nom. illeg. Lonchocarpus neuroscapha var. martianus (Tul.) Benth., Fl. Brasil. 15(1): 278; tab. 100. 1862 ("Martiana"). Tipo: Brasil, Martii Herbar. Florae Brasil. 1159 (Holótipo: P!; Isótipos: K!, LE!). Syn. nov.

Nomes populares: cabelouro (Bahia), embira-branca (São Paulo), embira-d'anta, embira-de-macaco (Espírito Santo), embira-de-carrapato (Minas Gerais), embira-de-sapo (Distrito Federal, Minas Gerais, Rio de Janeiro, Santa Catarina, São Paulo), imbira-de-caboclo (Paraná), piaca (Pernambuco), rabo-de-macaco (Santa Catarina).

Fig. 1-8

Árvore 4-30 m alt., DAP 15-30(50) cm, ritidoma liso, cinéreo; ramos lenticelados, hialinos a ferrugíneo- pebescentes ou glabros. Estípulas não vistas. Folhas (5)7-9(11)-folioladas; pecíolo 2-4 cm compr., raque 4,5-9,5 $\mathrm{cm}$ compr., ambos pubescentes a glabrescentes; peciólulo 3-5 mm compr., castanho-escuro; folíolos 3-13 × 1,5-5 cm, opostos a subopostos (os basais), oval-oblongos, oblongos, elípticos a obovais, ápice obtuso a curto-acuminado, base arredondada ou cuneada, coriáceos a cartáceos, discolores, face adaxial verde-clara a escura, face abaxial verde-opaca, ambas as faces pubescentes, venação broquidódroma, nervuras secundárias proeminentes na face abaxial. Pseudorracemos 9,9-18 cm compr., axilares, densifloros, eretos, solitários ou até 3 nas terminações dos ramos desfolhados, assemelhando-se a uma panícula, rufo-tomentosos ou glabrescentes; eixo de $2^{\mathrm{a}}$ ordem 2,9-3 mm compr.; brácteas de $1^{\mathrm{a}}, 2^{\mathrm{a}}$ e $3^{\mathrm{a}}$ ordens, caducas; bractéolas $0,9-1 \mathrm{~mm}$ compr., orbiculares a oval-orbiculares, situadas na base do cálice, pubérulas, persistentes. Flores 11,8-14 mm compr., pétalas brancas ou róseas a lilás, pontuações ausentes, pedicelo 1-2 $\mathrm{mm}$ compr., pubérulos, hipanto $<0,5 \mathrm{~mm}$ compr.; cálice 2-3 $\times 3,1-3,2 \mathrm{~mm}$, cupuliforme, ferrugíneo-tomentoso, lacínios carenais 3 , raso triangulares, lacínio vexilar retuso; estandarte 8,8-9 × 9-10 mm, oblongo-orbicular, ápice arredondado e ligeiramente emarginado, base auriculada, seríceo-pubescente acima da unguícula na face interna, curtamente seríceo externamente, biapendiculado próximo às aurículas, unguícula 1,8-1,9 mm; alas 8,5-8,7 ×3,9-4 mm, falcadas a elíptico-falcadas, ápice obtuso, base auriculada, seríceas, unguícula 3,2-3,3 mm compr.; pétalas da quilha 6,9-7 × 3,5-3,6 mm, oblongo-falcadas, ápice arredondado, base obtusa, seríceas, umbonadas, unguícula 3,6-3,7 mm compr.; tubo estaminal 7,8-8 mm compr., glabro; ovário 5,9$6 \times 0,9-1 \mathrm{~mm}$, linear, seríceo-tomentoso, óvulos 6-8, estilete abruptamente curvo, glabro, estípite 1,6-1,7 mm compr. Legume indeiscente 5-9,5 $\times 1,9-2,3 \mathrm{~cm}$, falcado, oblongo a oblongo-elíptico, ápice obtuso a agudo, margem vexilar discreta (2-2,1 mm espes.), reta e sem região da sutura dos carpelos exposta, bordas aladas, constricto ou não entre as sementes, coriáceo a sublenhoso, glabrescente a curtamente seríceo-hialino ou rufescente. Sementes 1-3(4), 0,9-1 × 0,6$0,7 \mathrm{~cm}$, reniformes, lisas, castanho-claras.

Material selecionado: BRASIL. Alagoas: Quebrangulo, Reserva Biológica de Pedra Talhada, $9^{\circ} 15^{\prime} \mathrm{S}, 36^{\circ} 25^{\prime} \mathrm{W}$, 4/I/1994, fl., A. Cervi et al. 7339 (G). Amazonas: Atalaia do Norte, Rio Javari, fronteira entre Brasil e Peru, 4³3’S, 71040'W, 18/I/1989, fr., C.A.F. Cid et al. 9955 (K); Boca de Tejo, Rio Juruá, IV/1901, fl., E. Ule 5446 (K). Bahia: Conceição de Feira, margem esquerda do rio Paraguaçu, 12³2'35”S, 3903’06” W, 17/II/1981, fl., A.M. Carvalho et al. 543 (CEPEC, K); Itaberaba, Serra do Orobó, entrada da fazenda Leão dos Brejos, 12²8'11"S, $40^{\circ} 31^{\prime} 13$ ”'W, 425 m s.n.m., 28/V/2005, fr., L.P. Queiroz et al. 10714 (K, HUEFS); Jacobina, arredores de Sítio do

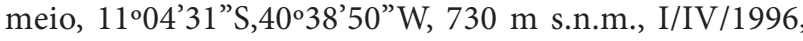
fr., R.M. Harley et al. 2744 (K, HUEFS). Distrito Federal: Brasília, Estação Ecológica da UnB, 17/XI/1980, fr., E.P. Heringer et al. 5726 (K, UEC). Espírito Santo: Conceição da Barra, 21/V/1999, G. Hatschbach et al. 69245 (G, K, $\mathrm{MBM})$. Goiás: Goiânia, Setor Goiânia II, às margens do rio Ribeirão João Leite próximo a ponte, 28/12/2010, fr., M.J. Silva 3234 (UFG). Minas Gerais: Andradas, à beira da estrada na saída da cidade, 7.I.1981, fl., H.F. Leitão-Filho et al. 12263 (K, NY, UEC); Belo Horizonte, Villa Maria Brazilina, 12/I/1940, fl., M. Barreto 10595 (BHCB, M). Paraná: Antonina, Manduíra, 4/I/1979, fl., G. Hatschbach 41832 (G, MBM); Guaratuba, Pedra Branca de Araraquara, 20/XII/1967, fl., G. Hatschbach 18162 (K, M, MBM); Rio Branco do Sul, 7/XII/1967, fl., G. Hatschbach 18059 (MBM, P). Pernambuco: Brejo da Madre de Deus, Mata do Buriti, 812' 27'S, 36²3'32”W, 19/I/2000, fl., A.G. Silva et al. 227 (K, PEUFR). Rio de Janeiro: Petrópolis, próximo ao rio Piabanha, 10/V/1867, fl., A. Glaziou 1029 (C, K, P); Saquarema, Morro dos Pregos, fazenda Santa Barbara, 12/I/2005, fl., H.C. Lima et al. 6227 (K, RB); Sete Pontes, Praia Grande, 1/II/1874, fl, A. Glaziou 12600 (K, C, P, US). Santa Catarina: Itajaí, Cunhas, 4/I/1955, fl., R.M. Klein 963 (B, FLOR, G, HB, PACA, US); Rio do Sul, Serra do Matador, 500 m s.n.m., 29/XII/1958, fl., R. Reitz 6074 (B, L, K, US); Sombrio, Pirão Frio, 28/I/1960, fl., R. Reitz \& R.M. Klein 4153 (G, K, M). São Paulo: Bom Sucesso de Itararé, 2417'57'S, 49¹2'54”'W, 19/XII/2007, fl., F. Chung et al. 233 (ESA); Itatiba, estrada próximo à rodovia Bragança Paulista na fazenda Santa Cristina, $23^{\circ} 00^{\prime}$ S, $46^{\circ} 34^{\prime} \mathrm{W}$, 14/XI/1995, fr., M. Sousa et al. 13383 (K, MEXU, UEC); Limeira, 26/XII/1932, fl., V. Emelen 127 (SP, SPSF).

Material adicional selecionado: Bolívia. Ballivian: Carretera Carinavi-San Borja, 1/XI/1989, fr., D.N. Smith \& V. García 13828 (G). Colômbia. Comisaría del Caquetá: Florencia, Quebrada del Río Dedo, 1/IV/1940, J. Cuatrecasas 8676 (INPA). Equador. Pastaza: Via Auca, $115 \mathrm{~km}$ south of Coca, 13/II/1989, fr., D. Nelly 8924 (G). Morona-Santiago: Yunganza ca. $15 \mathrm{~km} \mathrm{~N}$ of Limon, 800 m s.n.m., 19/XI/1982, fl., T.D. Pennington \& G. Tenorio 10780 (K). 

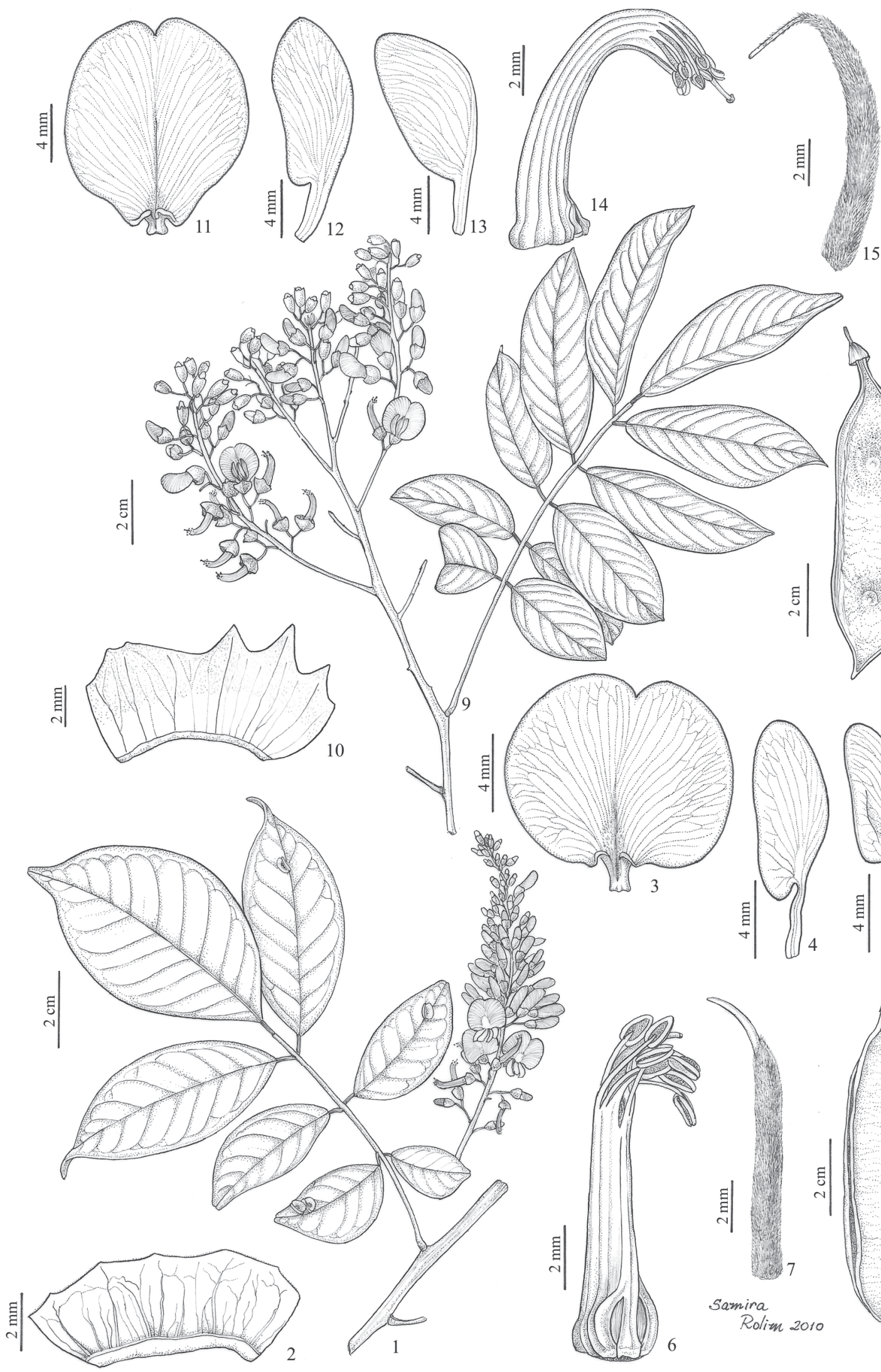

\section{0}

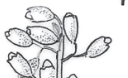
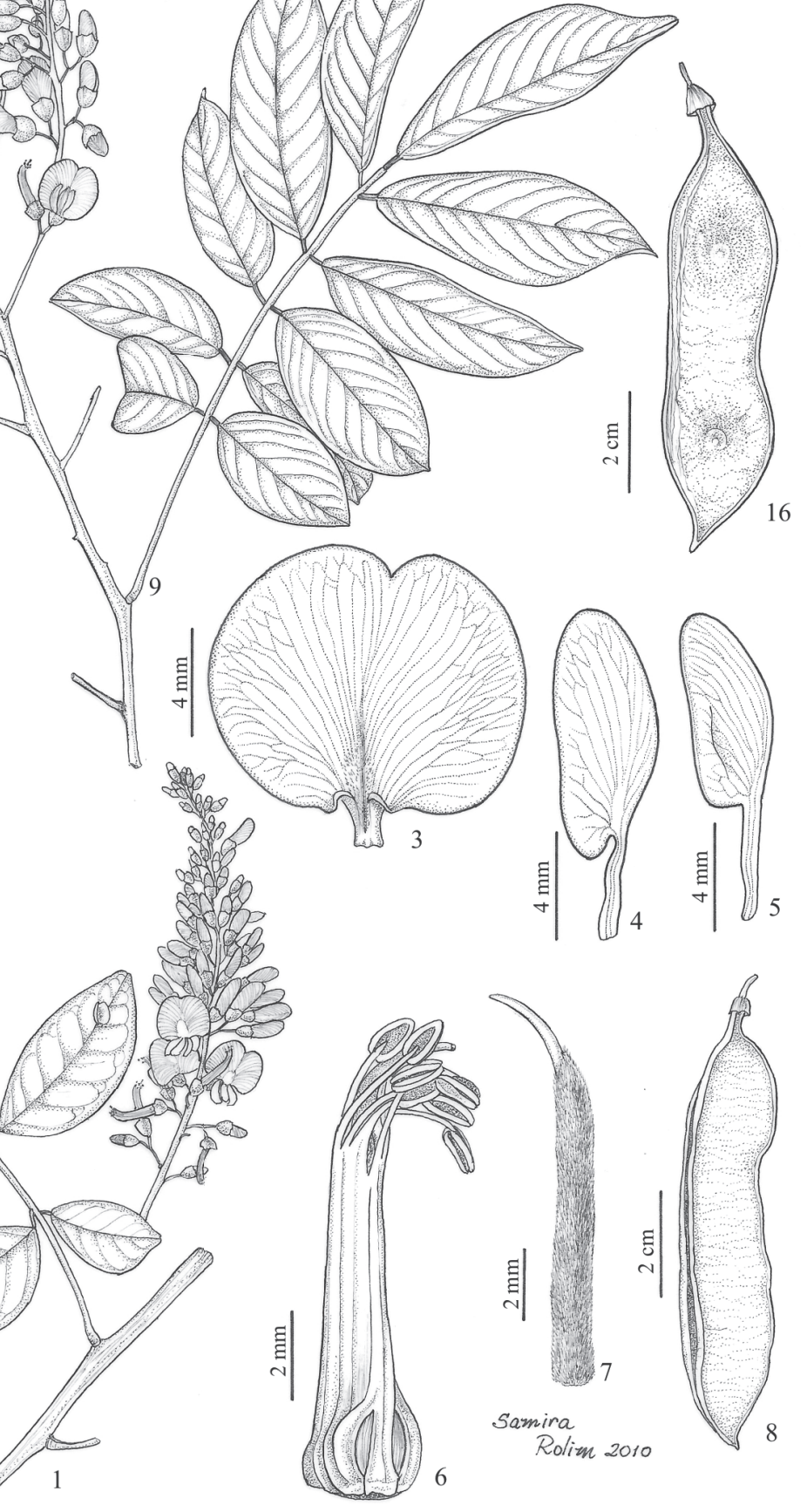

Figuras 1-8. Lonchocarpus cultratus (Vell.) A.M.G. Azevedo \& H.C. Lima: 1. Ramo florido; 2. Cálice rebatido; 3. Estandarte; 4. Ala; 5. Pétala da quilha; 6. Androceu; 7. Gineceu; 8 Fruto indeiscente. 9-16. Lonchocarpus hedyosmus Miq.: 9. Ramo florido; 10. Cálice rebatido; 11. Estandarte; 12. Ala; 13; Pétala da quilha; 14. Androceu; 15. Gineceu; 16. Legume samaroide. (1-7: Hatschbach 18162 - K; 8: Silva 3234 - UFG; 9-15: Ducke 17006 - G; 16 : Krukoff 10028 - SP). 
Distribuição e ecologia: espécie restrita a América do Sul (Bolívia, Brasil, Colômbia, Equador e Peru). No Brasil, é comum em todas as regiões, crescendo usualmente em matas ciliares ou de galeria associadas às florestas tropicais sazonalmente secas e úmidas. Também ocorre em locais pertubardos, como capoeiras ou pastagens. Pode ser encontrada em trechos da floresta amazônica, no Acre, no Amazonas e em Rodônia, de caatinga nos Estados de Pernambuco e Bahia e ainda de cerrado no Distrito Federal e Minas Gerais, sendo menos frequente nestes dois últimos biomas. Habita entre 10 e $1.200 \mathrm{~m}$ s.n.m., sobre solos arenosos a argilosos. Floresce e frutifica principalmente de novembro a abril, mas com maior índice de frutos entre abril e maio, embora sua frutificação estenda-se até setembro.

Caracterização e relacionamentos: Lonchocarpus cultratus é reconhecida pelos ramos jovens, pecíolo, raque e peciólulo esparsamente pubescente-hialinos a rufescentes, folíolos predominantemente elípticos, curto-acuminados e usualmente com galhas semelhantes a conchas na face adaxial, frutos glabrescentes a curtamente seríceo-hialinos ou rufescentes e com margem vexilar alargada e não exibindo a sutura carpelar, além de possuir flores sem pontuações. Compartilha da presença de galhas foliares com L. nitidus, L. sericeus e $L$. pluvialis, com as quais é frequentemente confundida a partir de material herborizado. Difere das duas primeiras pelos frutos com margem vexilar espessada, e da terceira principalmente pelas flores sem pontuações. Lonchocarpus nitidus e L. sericeus possuem frutos com margem vexilar nerviforme, sendo os da primeira espécie cartáceos e os de L. sericeus coriáceos a lenhosos. Lonchocarpus pluvialis possui flores com pontuações e frutos com margem vexilar bastante alargada. Alguns autores (e.g., Lewis 1987; Tozzi 1989) identificaram esta espécie como L. guilleminianus, um dos sinônimos de L. cultratus.

Bentham (1862) considerou a circunscrição de Neuroscapha na categoria específica e as espécies propostas por Tulasne (1843) como variedades: L. neuroscapha var. glabrescens (Neuroscapha guilleminiana), L. neuroscapha var. pubiger ( $N$. pubigera) e L. neuroscapha var. martianus (Neuroscapha martiana). Bentham (1862) descreveu ainda outra variedade, $L$. neuroscapha var. longeracemosus Benth., a qual deve ser considerada no gênero Deguelia. Lonchocarpus neuroscapha Benth. é um nome supérfluo porque está baseado no tipo de Neuroscapha martiana (Art. 52 do Código Internacional de Nomenclatura Botânica; McNeill et al. 2006), mas suas variedades não são ilegítimas (Art. 55.2).

2. Lonchocarpus hedyosmus Miq., Linnaea 18: 564. 1844. Derris hedyosma (Miq.) J.F. Macbr., Publ. Field Mus. Nat. Hist., Bot. Ser. 13: 262. 1943. Tipo: Suriname. Paramaribo: H. Focke 895 (Holótipo: U!).

Lonchocarpus paniculatus Ducke, Arch. Jard. Bot. Rio de Janeiro 3: 161. 1922. Tipo: Brasil. Pará; "in silvis circa Rio Branco de Óbidos", 31/X/1919, fl., A. Ducke s.n. (Lectótipo: RB 5314!, aqui designado; Isolectótipos: G!, K!, MG 45650!, MG 45651!, P!, RB!, S!, US!).
Lonchocarpus macrocarpus var. sericophyllus Benth., J. Linn. Soc., Bot. 4.(Suppl.): 91. 1860. Tipo: Peru. Loreto: "Prope Yurimaguas, in flumen Huallaga ripis", V/1855 ou VI/1856, R. Spruce 4597 (Hólotipo: K! [foto neg. 2739 NY!]; Isótipos: BM!, C!, F!, K!, LE!, P!).

Fig. 9-16

Nome popular: waiápi (Guiana).

Árvore 6-10(-20) $\mathrm{m}$ alt., tronco até $60 \mathrm{~cm}$ de circunferência; ramos lenhosos, subestriados, com lenticelas transversalmente elípticas ou oblongas, rufo tomentosos quando jovens, glabros quando adultos. Estípula 5-6 $\mathrm{mm}$ compr., linear-lanceolada, tomentosa externamente. Folhas (9)11(15)-folioladas; pecíolo 4-5 cm compr., raque 9-14 cm compr., ambos tomentosos; peciólulo 4-5 $\mathrm{mm}$ compr., seríceo-tomentoso; folíolos 4-11 $\times 2,3-4$ $\mathrm{cm}$, opostos a subopostos ou raramente alternos, comumente elípticos, às vezes elíptico-lanceolados, ovais (os basais) ou elíptico-obovais (os terminais), ápice agudo a acuminado, mucronulado, base largamente obtusa, raramente oblíqua, membranáceos a cartáceos; face adaxial curtamente serícea, face abaxial velutina-canescente, venação eucamptódroma, nervuras principal, secundárias e terciárias proeminentes e amareladas na face abaxial. Pseudorracemos 15-22 cm compr., axilares, solitários, ou em número de 8-12 nas terminações de ramos desfolhados e neste caso formando uma panícula de pseudorracemos, densifloros, congestos, tomentosos, lenhosos; eixo de $2^{\mathrm{a}}$ ordem 3,9-4 mm compr.; brácteas $1^{\mathrm{a}}$ ordem 2-3 mm compr., deltoides a oval-orbiculares, acuminadas, persistentes; bráctea de $2^{\mathrm{a}}$ ordem ca. $4 \mathrm{~mm}$ compr., linear-lanceolada; bráctea de $3^{\mathrm{a}}$ ordem $0,9-1 \mathrm{~mm}$ compr., oval; bractéolas 1-2 mm compr., linear-lanceoladas, subopostas, situadas no terço superior do pedicelo; brácteas e bractéolas, tomentoso-canescentes. Flores 19-22 mm compr., pétalas púrpuras a violáceas; pedicelo $2-3 \mathrm{~mm}$ compr., seríceo cálice e corola sem pontuações, hipanto ca. 0,5 mm compr.; cálice 5-6 ×6-8 mm, campanulado, tomentoso-seríceo externamente e na porção superior da face interna, dentes vexilares 3 , triangulares e acuminados, dente vexilar superior retuso; estandarte 12-13 × 13-13,2 $\mathrm{mm}$, oboval-orbicular, ápice arredondado e ligeiramente emarginado, base largamente atenuada, biapendiculada; bicaloso, calos transverso-lineares, curtamente seríceo acima da unguícula, densamente seríceo externamente, unguícula 0,9-1 mm compr., carnosa; alas 9,4-9,5 × 4,8-4,9 $\mathrm{mm}$, falcadas, esparso-seríceas ao longo das nervuras na face externa; unguícula 3,5-3,6 mm compr., ápice obtuso, base subtruncada; quilha 7,8-8 × 4,8-4,9 mm, falcadas, ápice agudo, serícea externamente, unguícula 3,6-3,7 mm compr.; tubo estaminal 9,8-10 × 1,1-1,2 mm; ovário 10-11 $\times 0,9-1 \mathrm{~mm}$, linear, seríceo-hialino a amarelados; óvulos 8 ; estilete seríceo no lado vexilar, geniculado. Legume samaroide 6,5-12 ×2-2,5 cm, oblongo, ápice e base agudos, ligeiramente constricto entre as sementes, margem vexilar alada (ala ca. $1 \mathrm{~mm}$ compr.), compresso, subcoriáceo, 
seríceo, tricomas amarelo-dourado. Sementes 1-4, 1,1-1,2 $\times 0,9-1 \mathrm{~cm}$, reniformes, castanhas.

Material selecionado: Brasil. Acre: Porto Alegre, rio Amajarí, 23/III/1848, fl., R.L. Fróes 23082 (P, RB). Pará: Rio Branco de Óbidos, 1/III/1918, fl., A. Ducke 17006 (BM, G, P, R); ib., in silvis circa Rio Branco de Óbidos, 31.X.1919, fl., A. Ducke 5314 (G, K, P, S, US, fotografia F neg 2317); ib., 26/XII/1913, fr., A. Ducke 15250 (BM, MG, NY).

Material selecionado adicional. Bolivia. La Paz: S. Yungas, Basin of rio Bopi, 750-900 m s.n.m., 1-22/VII/1939, fr., B.A. Krukoff 10028 (G, K, SP). Santa Cruz: Sara, 16/VI/1927, fr., J. Steinbach 7902 (BM, G, K). Colômbia: Along left bank of River Orinoco just below mouth os River Atabapo, 125 m s.n.m., 6/VIII/1959, fr., J.J. Wurdak \& L.S. Adderley 4375 (K). Guiana. Rupununi near rancho Shirley Humphries, $2^{\circ}$ $58^{\prime} \mathrm{N}, 59^{\circ} 39^{\prime} \mathrm{W}, 140-150 \mathrm{~m}$ s.n.m., 27/II/1985, fl., M.J. Jansen-Jacobs et al. 461 (B). Peru. Mayanas: Huallaga, VI/1856, fr., R. Spruce 4597 (K). San Martin: Tarapoto-Juanjui, Km 12, 60 40.3 'S, 76² $29^{\prime} \mathrm{W}, 250-300$ m s.n.m., 20/XI/1999, fl., T.D. Pennington \& A. Daza 16750 (K). Venezuela. Bolívar: entre El Cristo e La Paragua rumbo al Rio Pão, 8/III/1959, fl., Bernardi, A.L. 7407 (G); Utapa, Santa María IV/1947, fl., F. Cardona 2132 (G); Bosque de Mata Negra, cabeceras del Guanipa, 23/VI/1941, fr., H. Pittier 14880 (G); Rio Atabapo, Territorio Amazonas, Rio Atabapo at forest edge at San Fernando de Atabapo, 6/VI/1959, fl., J.J. Wurdack \& L.S. Adderley 42843 (G, K, P).

Distribuição e ecologia: Lonchocarpus hedyosmus ocorre no noroeste sulamericano (Bolívia, Brasil, Colômbia, Guiana, Peru, Suriname e Venezuela), em bordas de florestas úmidas, sopés de cordilheiras ou próxima a rios, entre 200-900 m s.n.m., crescendo sobre solos argilosos e úmidos. Floresce de novembro a abril e frutifica de maio a julho e em janeiro.

Relacionamentos e caracterização: Entre as espécies encontradas no Brasil, a que mais se assemelha a Lonchocarpus hedyosmus é L. margaritensis, por ambas compartilharem folíolos com face adaxial velutina, panícula de pseudorracemos quando nas terminações dos ramos, brácteas de $1^{\text {a }}$ ordem persistentes, estandartes densamente indumentados externamente e frutos com pubescência densa e amarelo-dourada quando maturos. No entanto, em L. hedyosmus, os pseudorracemos medem $15-22 \mathrm{~cm}$ compr. e são lenhosos (vs. 6,5-7 cm compr. e delgados em L. margaritensis), possuem eixos de $2^{\mathrm{a}}$ ordem de 3,5-4 mm compr. (vs. ca. 1,2 $\mathrm{mm}$ compr.), as flores medem $19-22 \mathrm{~mm}$ compr. (vs. 12-14,5 mm compr.), o ovário tem 8 óvulos ( $v s .4$ ou 5 ) e o estilete é geniculado e seríceo ( $v s$. parcialmente reto e glabro).

Nomenclatura e tipificação: Bentham (1860) comentou que $L$. sericeus e $L$. hedyosmus poderiam ser coespecíficas e estabeleceu L. macrocarpus var. sericophyllus indicando que a mesma assemelhava-se também a $L$. sericeus pelas folhas e pubescência, o que fez com que alguns materiais herborizados pertecentes a $L$. hedyosmus fossem interpretados como L. sericeus. Percebendo isto, Kleinhoot (1933) informou que $L$. sericeus diferia de L. hedyosmus por características dos frutos, folíolos e flores, o que foi corroborado por Tozzi (1989) e mantido aqui. Bentham (1860) citou também uma possível variedade de L. sericeus ("bracteolis parvis"), mas maninfestou dúvidas quanto ao estabelecimento dessa variedade por não ter examinado seus frutos. A análise das coleções citadas por Bentham (1860) em sua possível variedade, no entanto, mostrou que elas pertecem a espécies distintas: Hostmann 234 corresponde a L. hedyosmus e Linden 2138 a L. sericeus. A lectotipificação de Lonchocarpus paniculatus foi necessária porque a coleção-tipo contava com material florido, datado de $31 / \mathrm{X} / 1919$, e com material frutífero, datado de 11/I/1920. O material em floração foi escolhido por estar em boas condições e refletir a diagnose original da espécie.

3. Lonchocarpus latifolius (Willd.) DC., Prodr. 2:260. 1825. Amerimnum latifolium Willd., Sp. Pl. 3: 909. 1802. Derris latifolia (Willd.) Ducke, Bolm. Téc. Inst. Agron. N. 18: 195. 1949. Tipo: Colômbia. Cartagena: C.L. Willdenow 13088 (Holótipo B [fotografia UEC!]).

Dalbergia pentaphylla Poir., Encycl., Suppl. 2(2): 445. 1812. Lonchocarpus pentaphyllus (Poir.) DC., Prodr. 2: 259. 1825. Tipo: Porto Rico. M. Ledru s.n. (Holótipo: P!).

Dalbergia heptaphylla Poir., Encycl., Suppl. 2(2): 446. 1812. Lonchocarpus heptaphyllus (Poir.) DC., Prodr. 2: 259. 1825. Tipo: República Dominicana. Santo Domingo: P.A. Poiteau s.n. (Holótipo: P!; Isótipo: G!).

Lonchocarpus swartzii DC., Prodr. 2: 261. 1825. Robinia sepium Sw., Fl. Ind. Occid. 3: 1258, 1806, nom. illeg., non Jacq. 1760. Tipo: América Central. O. Swartz s.n. (Holótipo: C!).

Lonchocarpus discolor Huber, Bol. Mus. Paraense Hist. Nat. 3: 421. 1902. Tipo: Brasil. Pará: Breves, "furo Mucujubim”, M. Guedes s.n. (Holótipo: MG!; Isótipos: BM!, US! [foto neg. $28160 \mathrm{G}$ !, MG 45652!, MG 45653!]).

Fig. 17-24

Nomes populares: bara-karu, black-haiari, liane-a-enivrer-les-poissons, nicou (Guiana, Guiana Francesa), dogwood (Panamá), palo-hediondo (Porto Rico), tocorito (Venezuela).

Árvore 3-13 m alt., tronco com casca lisa ou estriada, castanho- a cinza-amarelada; ramos estriados, glabros, lenticelas pequenas, castanhas a esbranquiçadas, quando jovens, pubérulos, cilíndricos, fistulosos em seção transversal, mimercófilos. Folhas 5-7(9)-folioladas; pecíolo 8,5-12 $\mathrm{cm}$ compr., raque 3-8 cm compr., ambos cilíndricos, não subalados, glabrescentes; pulvínulo 2,5-5 mm compr., glabro; peciólulo 5-8 mm compr.; canaliculado, folíolos 8-16 $(-24) \times 3-8(-12) \mathrm{cm}$, opostos, predominantemente elípticos, raramente ovais a oval-lanceolados ou oboval-elípticos, ápice curto acuminado, base subarredondoda ou largamente cuneada, membranáceos, papiráceos a cartáceos, discolores, face abaxial verde-escura, lustrosa, glabra, face abaxial verde-glaucescente, curto-serícea, venação eucamptódroma, 

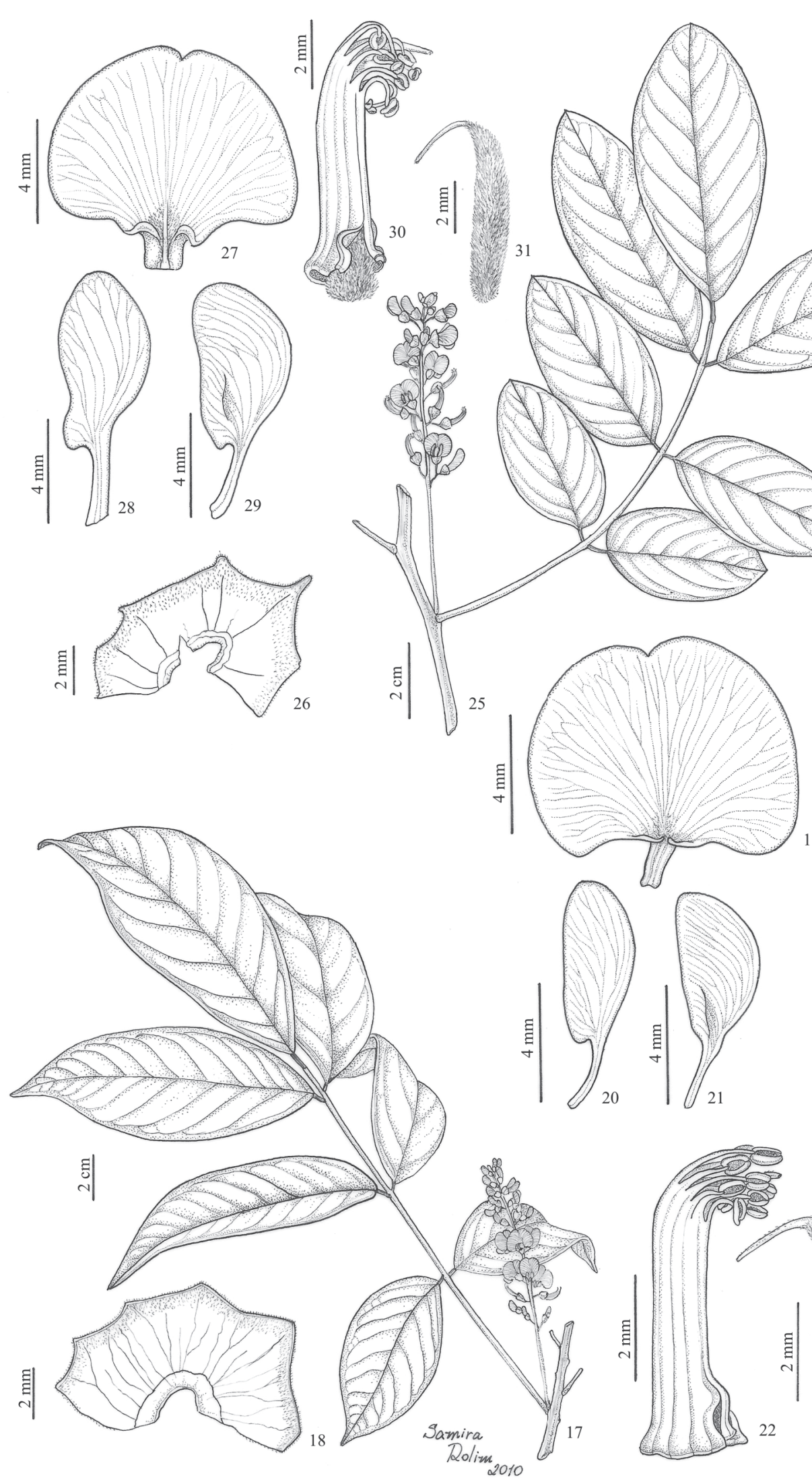

19
현
ㄴ.

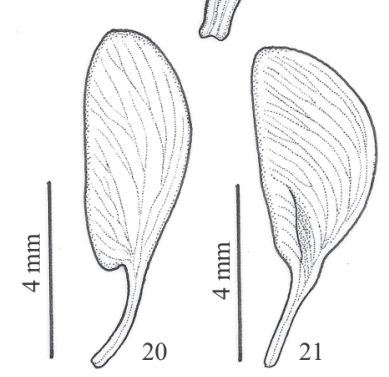

Figuras 17-24. Lonchocarpus latifolius (Willd.) DC.: 17. Ramo florido; 18. Cálice rebatido; 19. Estandarte; 20. Ala; 21. Pétala da quilha; 22. Androceu; 23. Gineceu; 24. Legume samaroide. 25-32. Lonchocarpus macrocarpus Benth.: 25. Ramo florido; 26. Cálice rebatido; 27. Estandarte; 28. Ala. 29; Pétala da quilha; 30. Androceu; 31. Gineceu; 32. Legume samaroide. (17-23: Davidse 3566 - B; 24: Nee 11020 - B; 25-31: Smith 3225 - K; 32: Milliken 449 - K). 
nervuras principal e secundárias proeminentes na face abaxial. Pseudorracemos 8-8,4 cm compr., axilares, solitários ou até 6 quando nas terminações de ramos desfolhados, densifloros, eixo de $1^{\text {a }}$ ordem delgado, eixos de $2^{a}$ ordem 1-2 mm compr., criso-tomentosos; brácteas de $1^{\mathrm{a}}-3^{\mathrm{a}}$ ordens 0,9-1 mm compr., ovais, pubescentes, tardiamente caducas; bractéolas 0,6-0,8 $\mathrm{mm}$ compr., oval-oblongas, tomentelas, persistentes, opostas, situadas no ápice do pedicelo. Flores 10-14 mm compr., pétalas vermelhas; cálice e corola sem pontuações; pedicelo 2-4 mm compr., criso-tomentelo, hipanto vestigial; cálice 2-3 ×3,5-3,6 mm, cupuliforme, base atenuada, rufo-tomentoso externamente, lacínios carenais 3, largo-triangulares, lacínio vexilar bífido; estandarte 6-7 $\times 7,8-8 \mathrm{~mm}$, suborbicular, base truncada, bicalosa, calos transverso-lineares, ápice arredondado, levemente emarginado, curto-seríceo externamente, unguícula 1,9-2 mm compr.; alas 5,2-5,3 × 2,2-2,3 mm, oblongo-falcadas, ápice arredondado, base subauriculada, seríceas externamente, unguícula 2,1-2,2 mm compr.; pétalas da quilha 4,9-5 $\times$ 2,7-2,8 mm, elíptico-obovais, seríceas externamente, ápice obtuso, umbonadas, unguícula 1,9-2 $\mathrm{mm}$ compr.; tubo estaminal 3-4 ×0,7-0,9 mm, anteras ovoides; ovário 4-4,2 ×0,7 $\mathrm{mm}$, linear, subséssil, seríceo, estilete 2,2-2,3 $\mathrm{mm}$ compr., curvo, glabro, óvulos 2-4. Legume samaroide 4,5-6,5 $\times$ $1,8-2,5 \mathrm{~cm}$, elíptico a semielíptico, ápice e base atenuados, compressos, margem vexilar nerviforme, cartáceo a papiráceo, criso-seríceo a glabrescente. Sementes 1-3, 8-13 × 6-7 $\mathrm{mm}$, subarredondadas, castanho-claras, compressas, lisas.

Material selecionado: BRASIL. Amazonas. Ad ripas fluvii Solimões super São Paulo de Olivença, s. d., fl., A. Ducke 18208 (G). Pará: estrada Belém Mosqueiro, 4/XI/1967, fl., J.M. Pires \& N.T. Silva 11266 (IAN); Ilha de Marajó, rio Genipapo, retiro São José, 30/I/1965, E. Oliveira 3459 (IAN); Ilha Mosqueiro, 3-9/XI/1929, fl., E.P. Killip \& A.C. Smith 30566 (US); Mosqueiro, 24/VIII/1941, fr., A. Ducke 771 (IAN); Oiapoque, Guiana brasileira, 17/VI/1904, A. Ducke s.n. (MG 4783); Vigia 17/XI/1948, J.M. Pires 1394 (IAC). Rio de Janeiro: Rio de Janeiro, cultivada no aterro do Flamengo, L.E. Mello Filho 2654 (R). São Paulo: Campinas, Bosque dos Jequitibás, 2/III/1978, fr., L. Mathes 10071 (UEC).

Material adicional selecionado: Belize. Toledo: Southern Maya Mountains: Bladen Nature Reserve, narrow valley botton around “AC Camp", 16 $29^{\prime} 44^{\prime}$ "N, 88 $8^{\circ} 54^{\prime} 47^{\prime \prime} \mathrm{W}, 250 \mathrm{~m}$ s.n.m., 7/V/1996, fl., G. Davidse 35666 (B, MO). Colômbia. Choco: Baudó, on the right side of Rio Baudo, about $19 \mathrm{Km}$ upstream from the estuary, 11/II-29/III/1967, H.P. Fuchs \& L. Zanella 22358 (K). El Valle: Costa del Pacífico, Bahia de Buenaventura, Quebrada de Aguadulce, 24/II/1946, fr., J. Cuatrecasas 20000 (P). Costa Rica. Playa Blanca road near Rincon de Osa, 16/II/1974, fl., R. Liesner 2185 (B, IJ). Cuba. Belmont Brook, Soledad, 21/IV/1908, fl., J.G. Jack 6017 (B). Dominica. Princes Rupers, IV/1882, fr., H. Eggers 743 (B). Guiana. Northwest, Koriabo, Rio Barima, 7-12/ IX/1934, W.A. Archer 2505 (US). Guiana Francesa. Rives de 1'Oyapock entre Georges e Maripa, III/1968, fl., R.A.A.
Oldeman 14441 (BM); Cayena, 1855, P.A. Sagot 125 (BM, K, P). Guadalupe. Macamba, N. Dame de Lourdes, 1880, A. Duss 681 (C). Haiti. Du Sud: Bouzi, Dabon, 24/VI/1980, fr., C. Sastre \& Y. Polynice 7029 (P). Honduras. Temax R., IV/1933, fl., N.S. Stevenson 166 (FHO). Jamaica. Parish: Negril, 7/X/1975, J.C. Proctor 35350 (IJ). Martinica. s. loc., s. d., M. Hahn 1504 (R). Panamá. Along of road to Cerro Pelado 0,5 km NW of Gamboa, 100 m s.n.m., 2/IV/1974, fr., M. Nee 11020 (B). Chiriqui: Burica Peninsula along streams on Quebrada Mellize, $6 \mathrm{~km}$ south of Puerto Armuelles, 150 m s.n.m., 5/III/1973, fl., R. Liesner 439 (B); Veraguas: Isla de Coiba, playa del campamento de Río Amarillo, 28/XI/1994, fl., Martín-Ballesteros et al. 800 (K). Porto Rico. Prope Bayamon, 1885, fl., A. Stahl 48 (B). República Dominicana. Rio Mameyes, 26/XI/1887, H. Eggers 1679 (L). Trinidad e Tobago. Lamana near to Bungaloo, 20/VII/1932, fr., R.C. Marshall 12669 (FHO). Venezuela. Monagas: Mérida, Guarapiche, 8/V/1966, fl., F.J. Breteller 5156 (K, L, P).

Distribuição e ecologia: Espécie distribuída desde a América Central (Belize, Costa Rica, Guatemala, Honduras, Nicarágua, Panamá), incluindo Antilhas (Cuba, Dominica, Guadaloupe, Haiti, Jamaica, Martinica, Porto Rico, República Dominicana e Trinidad \& Tobago), até a América do Sul (Brasil, Colômbia, Guiana, Guiana Francesa, Suriname e Venezuela). No Brasil, ocorre nos Estados do Pará e Amapá, em florestas úmidas (sensu Schrire et al. 2005), crescendo preferencialmente em margens inundadas de rios, em terreno de várzea sobre solos arenosos ou turfosos, desde o nível do mar até $800 \mathrm{~m}$. É cultivada para arborização de ruas e parques pela folhagem abundante e flores vermelhas, nos Estados de São Paulo, Minas Gerais e Rio de Janeiro. Floresce de fevereiro a setembro e frutifica de junho a setembro.

Caracterização e relacionamentos: Lonchocarpus latifolius é a única entre as espécies brasileiras a possuir flores vermelhas, o que a torna de fácil reconhecimento. Compartilha com L. spiciflorus os folíolos amplos, lustrosos e tão longos quanto largos, frutificação abundante e mimercofilia, visto que ambas abrigam formigas em seus ramos fistulosos. No entanto, L. latifolius possui pecíolo subcilíndrico e com margem não alada ( $v s$. anguloso e com margem alada em L. spiciflorus), frutos com margem superior nerviforme ( $v s$. alada) e pseudorracemos delgados e floríferos a partir de 2,5 cm da base ( $v s$. lenhosos e floríferos desde a base). Lonchocarpus latifolius assemelha-se a L. velutinus Benth. ex Seem. no aspecto delgado da inflorescência e tamanho delicado e diminuto das flores, porém em L. latifolius os frutos são cartáceos a papiráceos e elípticos a semielípticos (vs. membranáceos a papiráceos e linear-lanceolados em L. velutinus), as pétalas são seríceo-hialinas abaxialmente (vs. seríceo-douradas) e os folíolos possuem face abaxial curto-serícea ( $v s$. vilosa).

Robinia nicou Aubl., incluída na sinonímia de L. latifolius por Tozzi \& Silva (2007), trata-se de uma espécie de Deguelia. O tipo de Robinia nicou é composto por uma única folha, a qual se assemelha à folha de L. latifolius, mas também às 
folhas de algumas espécies de Deguelia. O protólogo de Robinia nicou (Aublet 1775), no entanto, apresenta descrição detalhada e ilustração das flores e frutos que sugerem que a espécie deve se tratada em Deguelia e não como sinônimo de L. latifolius, por exemplo: flores púrpura ( $v s$. vermelhas em L. latifolius), ramos sarmentosos, escandentes ( $v$ s. árvore) e folíolos glabros ( $v s$. curto-seríceos na face abaxial).

4. Lonchocarpus macrocarpus Benth., J. Linn. Soc. Bot. 4(Suppl.): 91. 1860. Tipo: Venezuela. Edo. Aragua: La Victoria, A. Fendler, 1861 (Lectótipo K!, designado por Pittier 1928 e Zamora 2011; Isótipos: C!, F! [foto neg. $2733 \mathrm{NY} !])$

Lonchocarpus margaritensis Pittier, Contr. U.S. Natl. Herb. 20(2): 91. 1917. Tipo: Venezuela. El Valle: Ilha de Margarita, 7/VII/1903, J.R. Johnston 23 (Holótipo: NY!; isótipos: $\mathrm{C}$ !, F!).

Lonchocarpus ernestii Harms, Repert. Spec. Nov. Regni Veg. 17: 321.1921 ('ernesti'). Derris ernestii (Harms) Ducke, Bol. Tecn. Inst. Agron. N. 18: 196. 1949. Tipo: Brasil. Rio Branco, Surumu, Serra do Mel, II/1910. E. Ule 8167 (Holótipo: K!; Isótipos: L!, US!, [fotos neg. 2730 NY!, neg. $2311 \mathrm{~B}$ !]).

Fig. 25-32

Nomes populares: jebe, majomo, majono-amarillo (Venezuela).

Árvore 10-20 m alt.; caule $20-30 \mathrm{~cm}$ de circunferência; ramos estriados, pubescentes ou pubérulos a glabrescentes quando adultos, esverdeados, delgados, densamente tomentoso-vilosos e ferrugíneos quando jovens, lenticelas pequenas, arredondadas, esbranquiçadas. Folhas (5)7-9(11)-folioladas; pecíolo 4-6 cm compr., raque 5,5$9,5 \mathrm{~cm}$ compr., ambos densamente vilosos, amarelados ou ferrugíneos; peciólulo 5-7 mm compr., tomentoso; folíolos 5,5-10 $\times 2-5 \mathrm{~cm}$, opostos, raramente subopostos, elípticos, oblongos a oblongo-lanceolados ou obovais, ápice agudo, raramente obtuso, base obtusa a oblíqua, subcartáceo a subcoriáceo, discolores, face adaxial verde-nítida, pubérula, face abaxial verde-opaca tomentosa a vilosa, tricomas esbranquiçados a ferrugíneos, venação eucamptódroma, nervuras secundárias proeminentes, amareladas. Pseudorracemos 5-6,4 cm compr., axilares, congestos, multifloros, solitários ou 3-10 nas terminações de ramos desfolhados, assemelhando-se a uma panícula, estriados, delgados, tomentoso-amarelados, eixo de $2^{\mathrm{a}}$ ordem até $1,2 \mathrm{~mm}$ compr, pubescente-amarelados; brácteas de $1^{\text {a }}$ ordem 2,9-3 mm compr., rômbicas, tomentosas, persistentes; bráctea de $2^{\mathrm{a}}$ ordem 2-3 mm compr., linear, tomentela, caduca; bráctea $3^{\text {a }}$ ordem até $1 \mathrm{~mm}$ compr., tomentela; bractéolas 1,9-2 $\mathrm{mm}$, linear-lanceolada, tomentosas, caducas, situadas na base do cálice, pontuações presentes. Flores 12-14,5 mm compr., pétalas rosadas, lilás ou avermelhadas, pedicelo 2-3 mm compr., hipanto ca. $1 \mathrm{~mm}$ compr.; cálice $3-4 \times 6-8 \mathrm{~mm}$, cupuliforme, marrom-avermelhado, lacínios carenais 3 , triangulares e acuminados, vexilar retuso, faixa de tricomas na porção apical da face interna; estandarte 7-7,1 × 8,9-9 $\mathrm{mm}$, orbicular-oval, ápice aredondado, ligeiramente emarginado, base subauriculada, seríceo externamente e acima da unguícula internamente, unguícula ca. $1 \mathrm{~mm}$ compr.; alas 5,9-6 × 3,4-3,5 mm, falcado-obovais, seríceas na face interna, base subtruncada, unguícula 2,1-2,2 mm compr.; pétalas da quilha 6,7-6,8 × 3,3-3,4 mm, falcado-obovais, densamente serícea na face externa, unguícula 2,3-2,4 mm compr.; ovário 5,1-5,2 × 0,9-1 seríceo-canescente, óvulos 4, estilete glabro. Legume samaroide $9-16,5 \times 2,8-3,5 \mathrm{~cm}$, elíptico ou semielíptico, base atenuada, compresso, longo-estipitado (estipe até $1,5 \mathrm{~cm}$ compr.), levemente constricto entre as sementes, margem vexilar nerviforme, cartáceo a subcoriáceo, reticulado, tomentoso-amarelado a dourado e brilhante. Sementes 1 ou 2, 1,1-1,2 ×0,8-1 cm, reniformes, castanho-claras a escuras.

Material selecionado: Brasil. Acre: São Marcos, entre os rios Tacutu e Uiraricuera, 3/X/1951, fr., G.A. Black 5113260 (COL, K, US). Amazonas: Boa Vista, Rio Branco, A. Ducke 1393 (K, RB, US). Roraima: Quadrícula NA-20-XB, 21/VI/1974, fr., J.M. Pires \& P.F. Lei 14661 (INPA); Reserva Ecológica de SEMA, Ilha de Maracá, $3^{\circ} 21^{\prime} \mathrm{N}, 61^{\circ} 33^{\prime} \mathrm{W}$, a oeste de Maracá, 17/VII/1987, fr., W. Milliken et al. 449 (K);

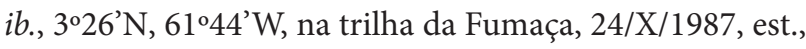
J.A. Ratter et al. 5867 (K, M).

Material adicional selecionado: Bolívia. Santa Cruz: orilla do rio Pirai, D'Orbigny s.n. (P). Guiana. Western extremity of Kanuku Mountains in drainage of Takutu River, 200 m s.n.m., 22/II/1938, fl., A.C. Smith 3225 (B, K, P). Peru. Prope Yurimaguas ao flumen Huallaga, Peruviae orientalis, R. Spruce 4597 (P). Venezuela. Guamitas, 16/ VI/1939, fl., A.F. Wilhens 11131 (K); Mérida: entre El Cristo y La Paragua, rumbo ao Rio Pao, 300 m s.n.m., 8/III/1959, fl., A.L. Bernardi 7409 (K).

Distribuição e ecologia: Endêmica do domínio amazônico sulamericano, sendo registrada para a Guiana e Venezuela (Tozzi 1989) e Brasil. Habita preferecialmente áreas próximas das correntezas de rios em ambientes savanoides, florestais úmidos ou sazonalmente secos, onde cresce desde solos areno-argilosos até rochosos em altitudes de 100 a 340 $\mathrm{m}$. Floresce de fevereiro a abril e frutifica de abril a julho, podendo também ser encontrada com frutos de setembro até novembro.

Relacionamentos e caracterização: Entre as espécies brasileiras, Lonchocarpus hedyosmus e L. latifolius, especialmente a primeira, são as que mais se assemelham a $L$. macrocarpus por compartilharem folíolos grandes e nítidos, com venação eucamptódroma. No entanto, os pseudorracemos delgados com flores delicadas, eixo de $2^{\mathrm{a}}$ ordem até 1,2 mm compr., o cálice cupuliforme com lacínios vexilares conspicuamente acuminados, juntamente com os frutos tomentoso-amarelados a dourados servem para identificar e diferenciar $L$. macrocarpus das demais espécies. Em $L$. hedyosmus, os pseudorracemos são robustos e possuem eixos de $2^{\text {a }}$ ordem diminutos ( $<1 \mathrm{~mm}$ compr.), enquanto 
em L. latifolius os pseudorracemos são delgados e possuem eixo de $2^{\mathrm{a}}$ ordem com 1-2 mm compr.

Nomenclatura: Lonchocarpus macrocarpus foi descrito com base em Fendler 1861 (Venezuela), Orbigny 578 (Bolívia) e "New Spain, Herb Pavón" (provavelmente México). Pittier (1928) designou Fendler 1861 como lectótipo de L. macrocarpus. Sousa (1990) julgou esta lectotipificação mecânica e designou a coleção "Herb Pavón s.n." (G!). Zamora (2011), estudando as coleções síntipicas deste nome, verificou que a coleção designada por Sousa (1990) corresponde a $L$. costaricensis (Donn. Sm.) Pittier e que o síntipo Orbigny 578 trata-se de L. hedyosmus, restabelecendo a lectotipificação feita por Pittier (1928). Dessa maneira, $L$. margaritensis é sinônimo de L. macrocarpus. Dada a grande uniformidade morfológica e praticamente a mesma distribuição geográfica, Tozzi \& Silva (2007) sinonimizaram $L$. ernesti em L. macrocarpus.

5. Lonchocarpus nitidus (Vogel) Benth., J. Proc. Linn. Soc., Bot. 4 (Suppl.): 92. 1860. Sphinctolobium nitidum Vogel, Linnaea 11: 419. 1837. Tipo: Brasil. Rio Grande do Sul; F. Sellow 1059 (Holótipo: B!; Isótipo: P!).

Fig. 33-40

Nomes populares: rabo-de-macaco (Argentina), canela-branca (Rio Grande do Sul).

Árvore 5-8 m alt.; ramos glabrecentes, estriados, lenticelados. Estípulas 2-3 mm compr., lanceoladas, persistentes. Folhas (5)7-9(11)-folioladas; pecíolo 2-3,5 cm compr. raque 3-8 cm compr., ambos subcilíndricos, puberulentos; peciólulo 2-4 mm compr., puberulento, enegrecido; folíolos 2,5-8,5 × 1-3,2 cm, opostos, predominantemente elípticos, às vezes lanceolados, ovais ou espatulados, base aguda a cuneada, ápice agudo a curto acuminado, cartáceos a coriáceos, verdes, discolores, face adaxial nítida, face abaxial opaca, ambas glabras, venação broquidódroma, nervuras secundárias imersas na face adaxial, proeminentes na abaxial. Pseudorracemos 4,5-5,5 cm compr., axilares, eretos, congestos ou laxos, delgados, glabrescentes, eixo de $2^{\text {a }}$ ordem 1-2 mm compr., tomentelo; bráctea de $2^{\mathrm{a}}$ ordem caduca; bráctea $3^{\mathrm{a}}$ ordem $0,8-1 \mathrm{~mm}$, oval, tomentela; pedicelo 2-3 mm compr., delgado, tomentelo; bractéolas 0,9-1 mm compr., largamente ovais, opostas, tomentelas, situadas na base do cálice. Flores 13,9-16 mm compr., pétalas azuis a lilás, pétalas e cálice sem pontuações; hipanto diminuto $(<1$ mm compr.); cálice 2,9-3 × 2-2,3 mm, campanulado, membranáceo, truncado, cinéreo-tomentoso; estandarte 0,9-1 $\times 0,9-1 \mathrm{~cm}$, orbicular, ápice aredondado, conspicuamente emarginado, base subtruncada, discretamente auriculada, bicalosa, calosidades falciformes, curto-seríceo acima da unguícula internamente, unguícula 1,9-2 mm compr.; alas 7,9-8 $\times 2-2,1 \mathrm{~mm}$, oblongo-falcadas, base auriculada, glabras externamente, unguícula 3,9-4 mm compr.; pétalas da quilha 6-6,1 $\times 3,9-4 \mathrm{~mm}$, oblongo-obovais, ápice aredondado, base atenuada; tubo estaminal $8-8,1 \times$ ca. $1 \mathrm{~mm}$ compr., anteras 0,9-1 mm compr., lanceoloides; ovário linear 6,9-7 mm compr., seríceo-incano, óvulos 6 ou 7, estilete 2,9-3 $\mathrm{mm}$, curvo, glabro. Legume samaroide 4,5-10 $\times 1-1,2 \mathrm{~cm}$, lanceolado, compresso, mas levemente globoso na região seminal, não constricto entre as sementes, sem artículos, glabrescente, cartáceo, amarelado, levemente reticulado, margem superior nerviforme, estipe ca. $1 \mathrm{~mm}$ compr. Sementes 1-6, 0,9-1 $\times 0,6-0,7 \mathrm{~cm}$, reniformes, globosas, macias, castanho-avermelhadas.

Material selecionado: Brasil. Paraná: Irati, $9 \mathrm{~km}$, ao sul de Irati, 2532'S, 5052’W, 800 m, 22/I/1965, fl., L.B. Smith \& R.M. Klein 14945 (K, MBM, P); Laranjeiras do Sul, Nova Laranjeiras, 17/XII/1965, fl., G. Hatschbach et al. 13375 (C, FLOR, HB, IJ, K, MBM, P, US); Sapopema, Salto das orquídeas-Passo do Meio, 22/XI/1998, fr., V.F. Kinupp et al. 980 (K). Rio Grande do Sul: Erechim, BR-153, R. Wasum et al. 11241 (G). s. loc., 16/I/1905, fl., B. Alfred 426 (M). Santa Catarina: Cerro Largo, 300 m s.n.m., 20/XII/1948, fl., A. Sehnem 3540 (B); Chapecó, Dionizio Cerqueira, 23.I.1952, fl., R. Reitz 4714 (M); Itapiranga, 20/II/1992, fr., G. Hatschbach et al. 56411 (MBM, UEC). São Paulo: Sete Barras, Núcleo Saibadela (Intervales), na trilha da encosta, $24^{\circ} 13^{\prime} 31^{\prime \prime S}, 48^{\circ} 12^{\prime} 51^{\prime \prime} \mathrm{W}, 12 / \mathrm{I} / 1999$, fl., D. Sampaio et al. 169 (ESA).

Material adicional selecionado: Argentina. Concepción: Misiones, 12.II.1947, fl., A.M.R. Huidobro 4793 (P). Federación: Entre Ríos, 26/III/1967, fr., T.M. Pedersen 8144 (C, K, P); Missiones: Santa Ana, 1901, fl., E. Hassler 706 (G); Oran, Rio de Las piedras, 350 m s.n.m., 9/XII/1911, fl. fr., M. Lillo 11017 (G). San Martín: Corrientes, 5 km E de Guaviraví, costa del río Uruguay, 13/II/1979, fl., A. Schinini, E. Cabral \& R. Vanni 17018 (CTES, K). Paraguai. Colonia: Rio San Juan, 6/I/1961, fl., A.L. Cabrera 13650 (M). Uruguai. Cocepción del Uruguay: $2 / 1877$, fl., P. Lorentz 888 (K, OXF). Paysandú: Dayman, VII.1934, est., $W$. Herter 1848 (G).

Distribuição e ecologia: Espécie sul-americana com distribuição na Argentina, Brasil e Uruguai. No Brasil, é registrada para as Regiões Sudeste (SP) e Sul (PR, SC), crescendo em matas de galeria associadas a florestas estacionais sazonalmente secas, em altitudes de 300-1.000 m. Floresce e frutifica entre dezembro e fevereiro, com pico de frutificação em março.

Relacionamentos e caracterização: Lonchocarpus nitidus pode ser diagnosticada pela combinação de folhas geralmente (5)7-folioladas, folíolos estreito-elípticos a lanceolados, pecíolo com 2-3,5 cm compr., pseudorracemos delgados e em geral do mesmo comprimento das folhas, e os frutos medindo 4,5-10 $\times 1-1,2 \mathrm{~cm}$. Assemelha-se morfologicamente a L. cultratus e a L. lilloi Burk., porém esta última espécie não ocorre no Brasil e a primeira possui frutos espessados na margem superior. Além disso, L. lilloi apresenta 3-5 folíolos, elípticos a largamente elípticos e tão largos quanto longos, pecíolo longo (5-7 cm compr.), pseudorracemos robustos e menores que as folhas, e frutos medindo 9-14,3 × 1,3-1,6 cm. 


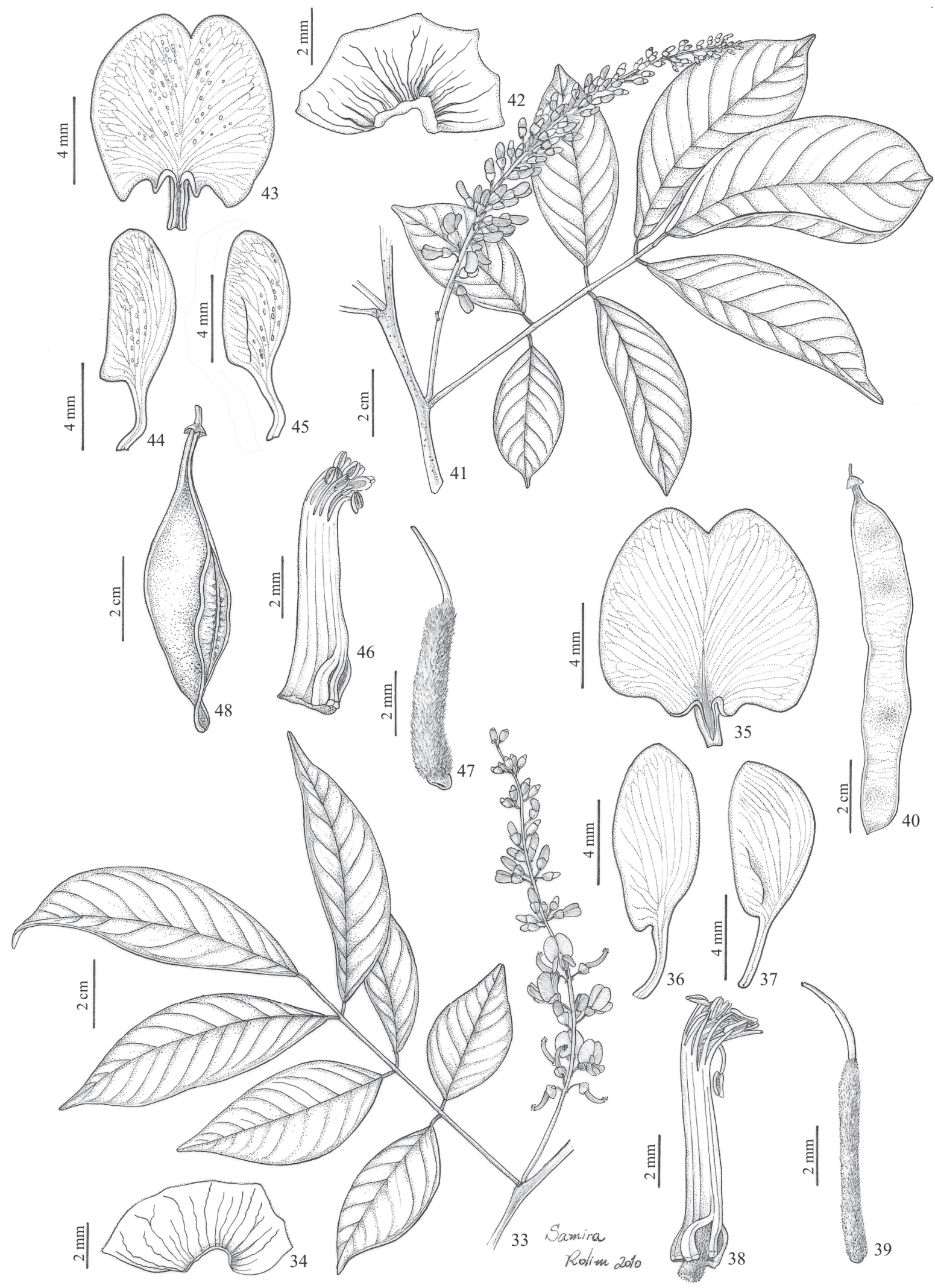

Figuras 33-40. Lonchocarpus nitidus (Vogel) Benth.: 33. Ramo florido; 34. Cálice rebatido; 35. Estandarte; 36. Ala; 37. Pétala da quilha; 38. Androceu; 39. Gineceu; 40. Legume samaroide. 41-48. Lonchocarpus pluvialis Rusby: 41. Ramo florido; 42. Cálice rebatido; 43. Estandarte; 44. Ala; 45. Pétala da quilha; 46. Androceu; 47. Gineceu; 48. Legume indeiscente. (33-39: Hatschbach 13375 - MBM; 40: Hatschbach 56411 - UEC; 41-47: Hatschbach 73927 - MBM; 48 : Damasceno 3263 - UEC). 
6. Lonchocarpus pluvialis Rusby, Mem. New York Bot. Gard. 7(3): 268. 1927. Tipo: Bolívia. Road from Rurrenabaque to Reyes, 22/X/1921, O.E. White \& H.H. Rusby 1302 (Holótipo: NY!; Isótipos: GH!, US!).

Derris steinbachii Harms, Notizbl. Bot. Gart. Berlin-Dahlem 10: 346. 1928. Tipo: Bolívia. Santa Cruz: Cercado, rio Piraí, 30/V/1925, fr., J. Steinbach 7119 (Holótipo: B destruído; Lectótipo: K!, aqui designado; Isolectótipos: F!, G!).

Lonchocarpus sericeus subsp. paraguariensis Hassl., Repert. Spec. Nov. Regni Veg. 8: 207. 1910. Tipo: Paraguai. Entre os rio Apa e Aquidaban, 7/XII/1908-1909, fl., K. Fiebrig 4389 (Holótipo: G!; Isótipos: K!, M!, GH!).

Vouacapoua pluvialis Rusby, Trop. Woods 6: 12. 1926, nom. nud.

Fig. 41-48

Árvore 10-20 m alt.; ramos jovens, pulvínulo, raque, pecíolo e peciólulo, tomentosos, indumento amarelados a marron, lenticelas arredondadas. Estípulas caducas. Folhas (5) 7-folioladas; pecíolo 2,5-3,2 cm compr.; raque 3,5-6,8 cm compr., ambos subcilíndricos; peciólulo 4-6 mm compr., folíolos 5,5-8 × 3,5-4 cm, opostos, largamente elípticos, elíptico-obovais a obovais, cartáceos, ápice obtuso a acuminado, base obtusa, membranáceos a cartáceos, discolores, face adaxial verde-nítida, ligeiramente bulada, indumentada sobre as nervuras e com galhas em forma de concha, face abaxial verde-opaca, tomentosa a velutina, tricomas dourados, venação broquidódroma, nervuras secundárias proeminentes, ligeiramente arqueadas. Pseudorracemos 9-12,5 cm compr., congestos, estriados, lenticelados e tomentoso-ferrugíneos, eixo de $2^{\mathrm{a}}$ ordem $3,5-4 \mathrm{~mm}$ compr.; bractéolas 1,2-1,3 mm compr., orbiculares, tomentelas externamente, presentes apenas no estádio de botão e com pontuações. Flores 12,3-13 mm compr., pétalas creme-amareladas, pontuações presentes; pedicelo 1,5-2 mm compr.; cálice 2,9-3 × 3,9-4 mm, campanulado, vináceo, curtamente seríceo-ferrugíneo externamente, truncado; estandarte 7,8-8 × 7,9-8 mm, orbicular, ápice arredondado, conspicuamente emarginado, base obtusa, apendiculada, seríceo externamente e próximo a unguícula na face interna; alas 7,4-7,5 × 2,9-3 mm, falcadas, ápice obtuso, base auriculada, unguícula 3,4-3,5 mm compr.; pétalas da quilha 5,9-6 $\times$ 2,9-3 mm, oblongo-falcadas, ápice obtuso, base obtusa; unguícula 2,8-2,9 mm compr.; tubo estaminal 5,2-5,3 mm compr., bicaloso basalmente, glabro, porção livre dos filetes até $1 \mathrm{~mm}$ compr.; anteras $0,3-0,4 \mathrm{~mm}$ compr., oblongoides, glabras; ovário 5,9-6 × 1,7-1,8 mm, linear, seríceo, óvulos 3 , estilete $2-2,1 \mathrm{~mm}$ compr., ligeiramente arqueado, indumentado da base. Legume indeiscente 3,5-11 × 1,2-1,3 cm, elíptico a oblongo-elíptico, castanho-dourado a ferrugíneo, ápice obtuso, base cuneada, margem vexilar conspícua encurvada exibindo a região da sutura carpelar, espessada (4,5-5 mm compr. de espessura), com quilhas encurvadas, estipe $0,4-1,2 \mathrm{~cm}$ compr. Sementes 1 ou 2, 1-1,1 × 1,1-1,2, largamente reniformes, castanho-escuras e lisas.
Material selecionado: Brasil. Espírito Santo: Tiradentes, na estrada sentido Valério-ES, ca. $45 \mathrm{~km}$ da cidade, 26/I/2007, fl., R. Tsuji et al. 1542 (ESA). Goiás: Formosa, $15^{\circ} 20^{\prime}$ S, $47^{\circ} 15^{\prime} \mathrm{W}, 25 / \mathrm{IV} / 1996$, fr., B.A.S. Pereira \& D. Alvarenga 2964 (IBGE, UEC). Mato Grosso do Sul: Bonito, rodovia Bonito para Campo dos Índios, Km 5-8, 9/XI/2002, fl., G. Hatschbach et al. 73927 (B, MBM, G); Corumbá, sopé da Serra Santa Cruz, Planalto Residual do Urucum, 200 m s.n.m., 17/XII/2003, fl., R.R. Silva \& J.S. Velásquez 662 (UEC); Corumbá, margem da rodovia BR-262, 30/ IX/1994, fr., G.F. Árbocz 855 (UEC); Ladário, fazenda São Marcelo, morro Santa Cruz, 400 m s.n.m., 19¹1'24,5”S, 57³4’52,5”W, 12/III/2002, fl., J. Damasceno \& J.S. Velásquez 3263 (COR, UEC). São Paulo: Teodoro Sampaio, Parque Estadual do Morro do Diabo, região do Angelim, 28/XI/1985, fl., O.T. Aguiar 151 (SPSF); ib., 23/VII/1986, fr., H.F. Leitão Filho et al. 12216 (SPSF, UEC).

Material adicional selecionado: Bolívia. El Beni: Cercado, Bosque del Rio Piraí, 450 m s.n.m., 30/V/1925, fr., J. Steinbach 7119 (K). La Paz: Sud Yungas, Alto Beni, área IV, Lote de Luis Cruz, 24/IV/1994, fr., E. Vargas 4048 (K). Cercado: bañado del rio Moreno, 28/X/1925, fl., J. Steinbach 7300 (G). Cordillera: ca. $20 \mathrm{~km}$ abajo de Camiri, 19³,18's, $63^{\circ} 27,8^{\prime} \mathrm{W}, 790 \mathrm{~m}$ s.n.m., 22/XI/2003, fl., J.R.I Wood et al. 20078 (K). Ichilo: $2 \mathrm{~km}$ WSW of El Hondo "Potrerillo", $17^{\circ}$ $40^{`}$ S, 63 $27^{\prime}$ W, 400 m s.n.m., 15/II/1994, fr., M. Nee \& I. Vargas C. 45028 (G, K). Nuflo de Chavez: east of San Javier on road to Concepción, 22/II/1995, fr., J.R. Abbott 16330 (G). Sara: Bañados del Rio Palometillas, 6/XII/1924, J. Steinbach 6719 (G, K). Santa Cruz: Andrés Ibanez, W side of city of Santa Cruz, 17²47'S, 6312'W, 420 m s.n.m., 3/XII/1989, fl., M. Nee 37932 (K); Chiquitos, entrada a Limoncito, 11/ XI/2007, fl., J.R.I. Wood et al. 23873 (K).

Distribuição e ecologia: Espécie sulamericana com ocorrência na Bolívia, Brasil (MS, GO, SP) e Paraguai. Cresce tanto na borda quanto no interior das florestas estacionais sazonalmente secas, em solos argilosos ou litólicos e ricos em minério de ferro ou em ambientes sazonalmente inundados, entre 106-424 m. Floresce em julho, entre novembro e janeiro, com abundância em dezembro, e frutifica entre fevereiro e julho, novembro e dezembro.

Relacionamentos e caracterização: Entre as espécies brasileiras, Lonchocarpus cultratus é a que mais se assemelha a L. pluvialis. Entretanto, a última possui ramos jovens, pecíolo, raque e peciólulo tomentoso-dourados a ferrugíneos, flores creme a amareladas, com pontuações, além de frutos tomentoso-amarelados a ferrugíneos, com face superior bastante alargada, exibindo o local da sutura carpelar, com margens encurvadas. Em L. cultratus os ramos jovens, pecíolo, raque e peciólulo são espassamente pusbescente-hialinos a rufescentes, as flores são brancas, rosa ou magentas, sem pontuações, e os frutos desde glabrescentes a seríceo-hialinos ou rufos, com margem superior pouco alargada, discreta, com bordas retas, não exibindo a sutura carpelar. 
7. Lonchocarpus sericeus (Poir.) Kunth ex DC., Prodr. 2: 260. 1825. Robinia sericea Poir., Encycl. 6(1): 226. 1804. Derris sericea (Poir.) Ducke, Bol. Tecn. Inst. Agron. N. 18:195. 1949. Tipo: M. Vahl s. n. (Holótipo: P!).

Dalbergia dominguensis Turp. ex Pers., Syn. Pl. 2: 276. 1807. Lonchocarpus turpinii Kunth in HBK, Nov. Gen. Sp. (quarto ed.) 6: 385 1824. Lonchocarpus dominguensis (Turp. ex Pers.) DC., Prodr. 2: 259 1825. Tipo: P.Turpin s.n. (Holótipo: P!).

Lonchocarpus macrophyllus Kunth in HBK, Nov. Gen. Sp. (quarto ed.) 6: 384. 1824. Dalbergia macrophylla Spreng., Syst. 4 Curr. Post. 268. 1827. Tipo: A. Bonpland 1571 (Holótipo: P!).

Lonchocarpus formosianus DC., Prodr. 2: 2601825 ('Formosianus'). Robinia violacea P. Beauv., Fl. Oware 2: 28; tab. 76. 1805-1820, nom. illeg., non Jacq. 1760. Tipo: $P$. Beauvois s.n. (Holótipo: G!).

Lonchocarpus pyxidarius DC., Prodr. 2: 260. 1825. Tipo: Caribe. R.L. Sagra s.n. (Hort. Bot. Havan.!).

Lonchocarpus tomentosus Tul., Arch. Mus. Par. 4: 82. 1844. Tipo: Brasil. Mato Grosso: s. loc., 1833, C. Gaudichaud 232 (Holótipo: P!).

Lonchocarpus sericeus var. jamaicensis Griseb., Fl. Brit. W. I.: 200. 1860. Tipo: Jamaica. A.W. Purdie s.n. (Holótipo: GOET; Isótipo: K!). Syn. nov.

Lonchocarpus lucidus Pittier, Contr. U.S. Natl. Herb. 20(2): 77. 1917. Lonchocarpus sericeus var. glabrescens Benth., J. Linn. Soc. 4 Suppl.: 89. 1860,. nom illeg. Tipo: Costa Rica. Santo Domingo de Osa, III/1896, A. Tonduz 9950 (Holótipo: US!).

Fig. 49-56

Nomes populares: cabelouro (Bahia), guará-timbó, ingá, ingá-bravo, ingá-de-bucha, ingá-pena-de-buchas, ingá-im, ingareira-piaba (Ceará), muxibeira (Maranhão), ingá-do-uruçu, ingá-hí (Espírito Santo), ingarana (Piauí), piaca ou priaca (Paraíba, Pernambuco).

Árvore 10-30 m alt., DAP $15-30 \mathrm{~cm}$, casca amarelo-acinzentada, ligeiramente rugosa, não fissurada; ramos eretos a pendentes, os mais jovens ferrugíneo-pubescentes ou tomentosos a glabrescentes, marrom-esverdeados, com lenticelas brancas. Estípulas 2,9-3 mm compr., ovais, ferrugíneo-tomentosas, caducas. Folhas (5)7-9(11)-folioladas; pecíolo 3-4 cm compr., raque 4,5-9 cm compr., ambos estriados, pubescentes; peciólulo 3-6 mm compr., estriado, ferrugíneo-pubescentes, folíolos 4-13 × 3-6,5 cm, opostos, oval-oblongos, a elíptico-obovais, raro elípticos, ápice obtuso ou arredondado ou curto-acuminado, base geralmente oblíqua-arredondada, coriáceos ou cartáceos, discolores, face adaxial verde-escura, nítida, ligeiramente bulada, pubérula a glabra, face abaxial verde-opaca, ferrugíneo-tomentosa, principalmente sobre as nervuras ou glabrescente, venação broquidódroma, nervuras proeminentes na face abaxial. Pseudorracemos 7-12 cm compr., axilares, solitários, densifloros, eretos lenhosos, estriados, velutino-pubescentes, tricomas ferrugíneos, eixos de $2^{\mathrm{a}}$ ordem 2-3 mm compr., densamente ferrugíneo-pubescente; brácteas de $1^{\text {a }}$ ordem ca. $8 \mathrm{~mm}$ compr., largamente ovais, pubescentes, caducas; brácteas $2^{\text {a }}$. ordem ca. $8 \mathrm{~mm}$, brácteas de $3^{\mathrm{a}}$ ordem ca. 0,7 mm compr.; bractéolas 1,9-2 mm compr., oval-orbiculares, pubescentes, persistentes. Flores 17-25 mm compr., pétalas rosadas a púrpura; hipanto $<1 \mathrm{~mm}$ compr.; cálice $4-5$ $\times 3-3,8 \mathrm{~mm}$, cupuliforme, tomentoso a velutino-pubescente externamente, tricomas ferrugíneos, marrom-esverdeados ou amarelados, lacínios carenais 3 , raso-triangulares, lacínio vexilar ligeiramente bífido; estandarte 11-16 × 11-13 mm, suborbicular, ápice arredondado e ligeiramente emarginado, base atenuada, biauriculada, bicalosa, densamente seríceo-canescente externamente, unguícula 2-2,3 mm compr.; alas 10,9-11 $\times$ 4,9-5 mm, oblongo-obovais, ápice obtuso, base auriculada, serícea externamente, unguícula 2,9-3,3 mm compr.; pétalas da quilha $8,8-8,9 \times 3,2-3,4 \mathrm{~mm}$, subfalcadas, ápice arredondado, base truncada, seríceas externamente; tubo estaminal 9-11 mm compr., amarelado, glabro; ovário 9-10 mm compr., linear séssil, base espessada, canescente-tomentoso, óvulos 7, estilete 2,8-3 mm compr., ligeiramente curvo, seríceo. Legume indeiscente 11-12,5 × 2,6-3 cm, oblongo, oblongo-falcado, ápice assimétrico a truncado ou arredondado, base atenuada a cuneada, margem vexilar nerviforme, bordas espessadas, coriáceo a lenhoso, velutino-ferrugíneo, separando-se em artículos quando maturos. Sementes 1-3(-5) com 0,7-10 × 5-7 mm, arredondadas a oblongo-reniformes, castanho-escuras.

Material selecionado. Brasil. Alagoas: s. loc., 1838, fl., G. Gardner 1275 (B, K, P). Bahia: Cansanção, 17 km S.W. of Cansanção on the Queimadas road, $10^{\circ} 49^{\prime} \mathrm{S}, 39^{\circ} 03^{\prime} \mathrm{W} .300 \mathrm{~m}$ s.n.m., 22/II/1974, fl., R.M. Harley 16291 (CEPEC, HUEFS, M, RB); Casa Nova, 9³1'S, 412ㄱ'W, 8/IX/1981, fr., J.D.C.A. Ferreira 109 (HRB, K); Queimadas, a caminho de Cansanção, $10^{\circ} 55^{\prime}$ 'S, 39³8'W, 16/I/1997, fl., M.M. Arbo et al. 7288 (K, CTES). Ceará: Aiuaba, estação Aiuaba, Antonina do Norte, 6³5'S, 4007'W, 480 m s.n.m., 7/VI/1984, fr., J.E.R. Collares \& L. Dutra 192 (EAC, K). Espírito Santo: Linhares, margem do rio Ipiranga, 21/VIII/1991, fr., V. Souza 147 (ESA, K); São Mateus, na margem direita do rio Ipiranga no sentido de Uruçuaquara, 6/VII/1992, fr., V. Souza 350 (ESA, K, P). Goiás: Alvorada do Norte, rio Corrente, 10/X/1976, fl., G. Hatschbach et al. 39121 (K, MBM); Lavandeira, ca. $11 \mathrm{~km}$ de Lavandeira, em direção a Aurora do Tocantins, $12^{\circ} 43^{\prime} 23^{\prime \prime}$ S, 46 $27^{\prime} 43^{\prime \prime} \mathrm{W}, 480$ m s.n.m., 25/I/2005, fr., J. Paula-Souza et al. 4630 (ESA). Maranhão: Loreto, Ilha de Balsas, região entre os rios Balsas e Parnaíba na propriedade de Dona Luzia, 7³0'S, 4503'W, 140 m s.n.m., 27/V/1962, G. Eiten \& L. Eiten 4761 (K). Mato Grosso do Sul: Corumbá, $50 \mathrm{~m}$ a leste da rodovia MS-184, entre a curva do Leque e a fazenda Boa Sorte, $1^{\circ} 10^{\prime} \mathrm{S}, 57^{\circ} 01^{\prime} \mathrm{W}, 6 / \mathrm{XII} / 1986$, fl., C.N.D.A. Cunha et al. 2077 (K). Pará: rios Pacaja e Muirapiranga, $2^{\circ} 33^{\prime} \mathrm{S}, 50^{\circ} 38^{\prime} \mathrm{W}$, próximo ao rio Pacaja oposto a Ilha do Breu, 17/IX/1965, fl., G.T. Prance et al. 1316 (K, NY). Piauí: São Raimundo Nonato, $9^{\circ} 00^{\prime} \mathrm{S}, 42^{\circ} 00^{\prime} \mathrm{W}, 310 \mathrm{~m}$ s.n.m., 18/I/1982, fr., G.P. Lewis \& H.P.N. Pearson 1114 (CEPEC, K). 
Rio de Janeiro: entre Mataruna e Rio Bonito, 29/V/1877, fl., A. Glaziou 10552 (C, R, P). Roraima: Reserva Ecológica de SEMA, Ilha de Maracá, 3⒉ 'N $61^{\circ} 33^{\prime}$ W, W. Milliken et al. 450 (K). Tocantins: Aurora do Tocantins, na rodovia de Campos Belos à Taguatinga próximo ao rio Sobrado, 11/ II/1994, fr., G. Hatschbach et al. 60390 (K, MBM); Paranã, Rio Paranã, 400 m s.n.m., 10/XI/1991, fl., G. Hatschbach et al. 56048 (MBM, K).

Material adicional selecionado. Camarões. Southwestern Province, $4^{\circ} 53^{\prime} \mathrm{W}, 8^{\circ} 47^{\prime} \mathrm{N}$, Banks of Ndian R, between Bulu e Last Banana, 22/VII/1983, fl., D.W. Thomas 2350 (B). Colômbia. Cucuta: Santander, VI.1968, fl., C. Sandemann 6110 (OXF). Costa do Marfim. Litoral forest, Nero-Mer, $3 \mathrm{~km}$ E of Bereby, 8/XI/1963, fr., R.A.A. Oldeman 548 (B). Costa Rica. Guanacaste: Tilará, rio Chiquitos, bajos de San Pedro, $10^{\circ} 26^{~}$ N, 845' 'W, 650-700 m s.n.m., 16/I/1987, fl., E. Haber \& D. E. Bello s.n. (P). Cuba. Pinar del Río, 27/ VI/1905, fl., J.G. Baker 5263 (B). Guiana. Georgetown: Botanic Gardens, 27/IX/1934, fl., W.A. Archer 2564 (K). México. Acapulco and Vicinity, XI/1894, fr., E. Palmer 598 (P); Sinaloa: Rosário, Chametla, Coacoyolitos, XI/1925, fr., L.C.S. Ortega 5776 (M). Porto Rico. Guayanillo ad los Índios ad ripam fluminis, 29/VII/1886, fl. fr., I. Urban 4991 (M). República Dominicana. Paradis prope Barahama, I/1910, fl., Turckhein 2819 (M). Senegal. Basse-Casamance, Abéné, 29/I/1992, V.C. Berghen 9539 (B). Togo. entre Aklakou e Avévé, 6²2'N, 1²4’E, 19/VI/1985, fl., G. Schäfer 8558 (B). Trinidad e Tobago. Valencia, IX/1883, fl., H. Eggers 1182 (P). Venezuela. Merida: 27/VII/1917, fl., A.L. Bernardi 2883 (K). Bolívar: along road between $\mathrm{Km} 11$ and 18,5 south of El Dorado, 23/VII/1960, fl., J. Steyemark 86623 (P). Delta do Amacuro: between La Margarita and Puerta Miranda, Rio Acure, 80-100 m s.n.m., 26/XI/1960, fr., J. Steyermark $87791(\mathrm{M})$.

Distribuição e ecologia: Lonchocarpus sericeus é a espécie do gênero mais amplamente distribuída, ocorrendo desde o sul do México até a porção meridional da América do Sul, incluindo Antilhas e também a maior parte da costa ocidental africana. No Brasil, é registrada para todas as regiões, crescendo usualmente próxima às margens de rios em diversos tipos vegetacionais (florestas úmidas, tropicais sazonalmente secas, incluindo caatinga), entre altitudes de 200-1200 m, em solos usualmente argilosos ou hidromórficos. Floresce de junho a fevereiro e frutifica de maio a junho e de setembro a outubro.

Caracterização e relacionamentos: Lonchocarpus sericeus compartilha com L. latifolius, L. macrocarpus, L. hedyosmus e L. spiciflorus as folhas vistosas com folíolos grandes (3,5-19 $\times 2,3-9 \mathrm{~cm}$ compr.). No entanto, é fácilmente reconhecida pelos frutos coriáceos ou raramente lenhosos, não espessados na margem vexilar, tomentoso-ferrugíneos ou rufescentes, separando-se em artículos quando maturos, folíolos usualmente oval-oblongos a elíptico-obovais, com ápice obtuso a arredondado, flores grandes (até $16 \mathrm{~mm}$ compr.), com cálice subtruncado e bractéolas orbiculares e vistosas.
Nomenclatura: Bentham (1860) subordinou L. pyxidiarius e $L$. tomentosus à sinonímia de $L$. sericeus e tratou L. formosianus, $L$. dominguensis (= L. turpinii) e L. macrophyllus em L. sericeus var. glabrescens, criando um nome supérfluo para este táxon. Pittier (1917) considerou $L$. sericeus var. glabrescens no nível de espécies estabelecendo um nome novo, L. lucidus, aqui tratado como sinônimo de L. sericeus. Lonchocarpus sericeus var. jamaicensis é sinonimizada a $L$. sericeus porque as características usadas para o seu reconhecimento mostram-se contínuas às encontradas na variedade típica.

8. Lonchocarpus spiciflorus Mart. ex Benth., J. Linn. Soc., Bot 4(Suppl.): 91. 1860. Derris spiciflora (Mart. ex Benth.) J.F. Macbr., Publ. Field Mus. Nat. Hist., Bot. Ser. 13: 265. 1943. Tipo: Brasil. Pará: Rio Negro, 1820, fl., s.c., Martii Herb. Florae Brasil. 13832 (Lectótipo: M! aqui designado).

Fig. 57-64

Nomes populares: charapilla, tangarana-masha (Peru). Árvore 6-10 (20) m alt.; tronco 10-40 cm diâm.; ramos cilíndricos, fistulosos em seção transversal, estriados, lenticelados, glabros a pubérulos, ou quando jovens tênue-seríceos. Estípulas caducas. Folhas 7-9-folioladas; pecíolo 3,5-5,5 cm compr, raque $11-14 \mathrm{~cm}$ compr, ambos amplo-sulcados na face superior, angulosos, subalados marginalmente, glabrescentes; peciólulo 8-10 mm compr, enegrecido, sulcado na face superior; folíolos 3,5-19 × 3-9 $\mathrm{cm}$, opostos ou subopostos, os basais suborbiculares a ovais, os intermediários elípticos a oblongos, às vezes ligeiramente obovais, os terminais geralmente obovais, ápice arredondado, base arredondada a cuneada, coriáceos, discolores, face adaxial verde-escura, ligeiramente bulada, glabra ou esparso-pubérula, face abaxial verde-glaucente, esparso-estrigulosa, venação eucamptódroma, nervuras principal e secudárias proeminentes e amareladas. Pseudorracemos $15,5-20,7 \mathrm{~cm}$, eretos, axilares ou falsamente terminais quando na terminação de ramos desfolhados e, neste caso, com 2-4 pseudorracemos, multifloros, congestos, espessados e com aspecto espiciforme, estriados, eixos de $2^{\text {a }}$ ordem 1,2-2 $\mathrm{mm}$ compr., estriados, pubérulos; bráctea de $2^{\mathrm{a}}$ ordem ca. $1 \mathrm{~mm}$ compr.; bractéola $0,9-1 \mathrm{~mm}$ compr., suborbicular, tomentela, opostas, inseridas na base do cálice; pedicelo 1,8-1,9 mm compr. Flores 11,9-12,2 mm compr., pétalas brancas a cremes; cálice 3,4-3,5 × 3,8-4,2 mm compr., subtruncado, avermelhado, rufo-tomentelo; estandarte 6,7-6,8 $\times 8,9-9 \mathrm{~mm}$. suborbicular, bicaloso, biapendiculado, ápice arredondado, ligeiramente emarginado, base truncada, seríceo externamente, unguícula 0,9-1 mm compr.; alas 7,1-7,2 × 3,9-4 mm, obovais, base atenuada, esparso-seríceas externamente, unguícula 2,9-3 mm compr.; pétalas da quilha 7,0-7,1 $\times 4-4,1 \mathrm{~mm}$, obovais, base, atenuada, serícea externamente, unguícula $2,5-3 \mathrm{~mm}$ compr.; tubo estaminal 6-6,1 $\times 0,9-1 \mathrm{~mm}$; anteras $0,8-0,9 \mathrm{~mm}$ compr., lanceoladas; ovário 5,9-6,1 × $1 \mathrm{~mm}$ compr., linear, criso-tomentelo, 

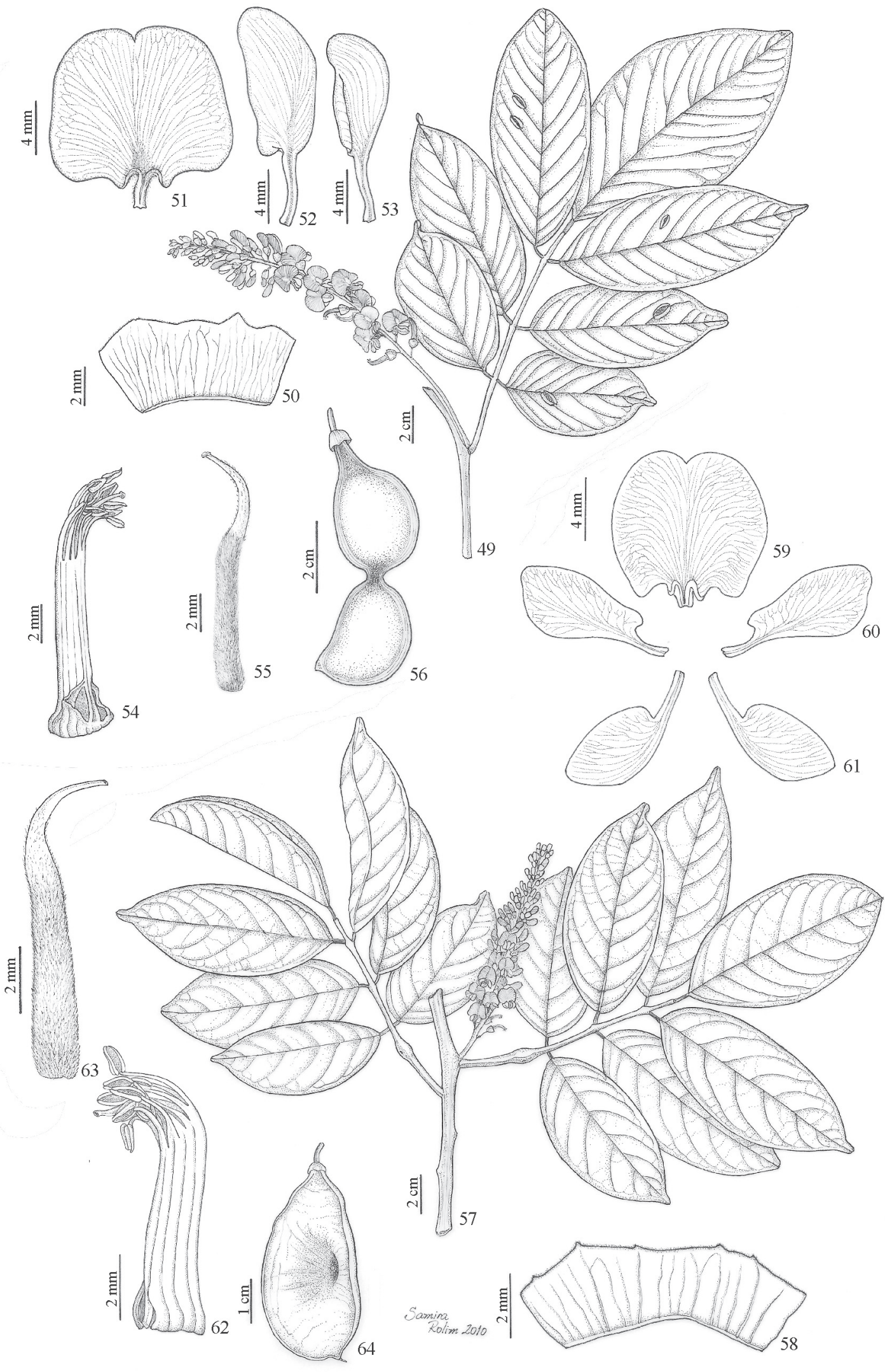
óvulos 4-5, estilete ca. $2 \mathrm{~mm}$ compr., ligeiramente curvo. Legume indeiscente 3,5-7 $\times 2,2-4,5$, oblongo a elíptico, constrito ou não entre as sementes, compresso, cartáceo, margem vexilar alada (ala ca. $2 \mathrm{~mm}$ larg.), castanho-claro a pardacento, liso, estriado próximo a margem, tomentelo, estipe 3-5 mm compr. Sementes 1-3, 1-1,1 × 0,8-0,9 mm, reniformes, castanho-claras a escuras.

Material selecionado. Brasil. Acre: rio Purus confluência com o rio Acre, 6/IV/1933, fl., A. Ducke 24310 (G, K, P). Amazonas: Alvarães, rio Solimões. 13/XII/1977, fl., C. Damião 2868 (INPA); ib., rio Solimões, oposto a boca do rio Juruá, 19/II/1977, fl., fr., G.T. Prance et al. 24502 (NY); Região de Juruá, na base do rio Juruá, na foz to Tarauaca, I/VI/1933, B.A. Krukoff 4605 (G, M, NY); São Paulo da Olivença, em locais inundados do rio Solimões, 26/I/1924, fl., J.G. Kuhlmann 18208 (K, P, R); ib., 27/II/1932, fl., A. Ducke 24309 (K, P); ib., 24/V/1940, fr., A. Ducke 551 (IAN, K, NY, ); rio Amazonas, border of Solimões river, 26/XII/1948, fl., R.L. Flóes 23811 (NY). Pará: Marajó, rio Genipapo, retiro São José, terreno de várzea, 30/IX/1965, fr., E. Oliveira 3457 (IPEAN); ib., Belém, cultivada atrás da seção de Botânica do I.A.N, 25/VIII/1953, fl., J. M. Pires 4517 (IPEAN). Rio de Janeiro: Material cultivado no Jardim Botânico do Rio de Janeiro, 15/III/1982, fr., G.P. Lewis s.n. (K).

Material adicional selecionado. Guiana. 1868, fl., R.H. Schomburgk 33 (P). Peru. Ost. Peru: Stromgebiet des Maranon von Iquitos aufwärts bis zur Santiago-Mündung am Pongo de Menseriche, ca. $77^{\circ} 30^{\prime} \mathrm{W}, 1924$, fl., G. Tessmann 5526 (G); Stromgebiet des Maranon von Iquitos aufwärts bis zur Santiago-Mündung am Pongo de Menseriche, ca. 77030'W, 1924, fl., G. Tessmann 5027 (G). Huánuco: Pachitea, Honoria, Bosque Nacional de Iparia, 19/VII/1967, fr., J. Schunke 2117 (COL, G). Loreto: Balsapuerto, $220 \mathrm{~m}$ s.n.m., II/1933, fl., G. Klug 2930 (BM, G, K, US); Requena, Jenaro Herrera, Supay, $5^{\circ} 00^{\prime}$ S, 73³0'W, 5/II/2001, fl. fr., T.D. Pennington et al. 17120 (K). Madre de Dios: 30/III/1981, fl., R.B. Foster \& C. Janson 8335 (K). Manu: Parque Nacional de Manu, Cocha Cashu Biological Station, 21/VIII/1976, fr., R. Foster \& C. Augsurger 3292 (K). Ucayali: Semuja, 16/III/1988, fl., J. Rios 1820 (K); Amazonas: Bagua, Imaza, camino Putuim-Shimutaz, 503'20"S, 78'20'23”W, $380 \mathrm{~m}$ s.n.m., 22/VI/1996, fr., R. Velásquez et al. 21339 (K). San Martín: Chazuta, Río Huallaga, 260 m s.n.m., III/1935, fl., G. Klug 3967 (K).

Distribuição e habitat: Lonchocarpus spiciflorus apresenta distribuição sulamericana com ocorrência registrada para a Amazônia brasileira, colombiana e peruana. No Brasil, a espécie ocorre nos Estados do Acre e Amazonas, nas bacias dos rios Solimões e Juruá. Cresce principalmente em margens alagadas de rios, em várzeas inundadas ou igarapés, mas sempre em florestas úmidas, entre 200 e 400 $\mathrm{m}$ de altitude. Floresce de dezembro a maio e frutifica de março a julho.

Caracterização e relacionamentos: Lonchocarpus spiciflorus é caracterizada pelos pseudorracemos multifloros, congestos, mais curtos que as folhas, com eixo principal robusto e pelo menos duas vezes maior que o comprimento do pecíolo, além de apresentar pecíolo e raque angulosos e subalados. Relaciona-se morfologicamente com L. latifolius, por compartilhar os ramos fistulosos e mimercófilos, folíolos tão longo quanto largos e frutificação abundante. No entanto, diferencia-se pelo fruto alado na margem superior ( $v s$. não alado em $L$. latifolius), pedicelo floral $<2 \mathrm{~mm}$ compr. (vs. $>2 \mathrm{~mm}$ ) e folíolos coriáceos ( $v s$. papiráceos).

Nomenclatura: O síntipo de Lonchocarpus spiciflorus inclui coleções de Martius e a coleção Poeppig 3107. Entretanto, Bentham (1860) não indicou números nem localidade para as coleções de Martius. Após análise destes síntípos e considerando que Bentham (1860) havia reconhecido Martius como autor do nome, a coleção Martius 13832 foi desiganada lectótipo deste nome. $\mathrm{O}$ material é fidedigno à diagnose original da espécie, conta com flores e está em bom estado de conservação.

9. Lonchocarpus violaceus (Jacq.) Kunth ex DC., Prodr. 2: 259. 1825. Robinia violacea Jacq., Enum. Syst. Pl.: 28. 1760. Tipo: Berten-Mr. Dalembert 1820 (Holótipo: G-DC!).

Lonchocarpus punctatus Kunth in HBK, Nov. Gen. Sp. (quarto ed.) 6: 383. 1824. Tipo: Venezuela. Cumaná: $A$. Humboldt \& A. Bonpland 1127 (Holótipo: P!). Syn. nov. Lonchocarpus benthamianus Pittier, Contr. U.S. Natl. Herb. 20(2): 86. 1917. Tipo: Martinique. "Collines Du bois Brûlé”, 1871, M. Hahn 1123 (Lectótipo: GH!, aqui designado).

Fig. 65-72

Nomes populares: aco, majono negro, nazareno, tocorito (Venezuela), jebe (Colômbia).

Árvore 5-10 m alt., casca lisa e acinzentada, às vezes descorticante; ramos cilíndricos, glabros, cinéreos a castanhos nas porções jovens, com numerosas lenticelas creme, arredondadas. Estípulas caducas. Folhas (7)9-11-folioladas; pecíolo 2,9-4,1 cm compr.; raque 7,3-9,5 cm compr., ambos glabros, raque às vezes fractiflexa; peciólulo 2-3 $\mathrm{mm}$ compr., rugoso; folíolos 6,3-8,2 × 1,9-3,5 cm, opostos a alternos, translúcido-punctados, glabros, elípticos a oval-elípticos, base oblíqua nos folíolos basais e intermediários e cuneada no folíolo terminal, discolores, face adaxial verde-escura, face abaxial verde-cinérea, venação broquidódroma, nervuras secundárias impressas, nervuras terciárias reticuladas. Pseudorracemos 11,1-12,2 cm compr., axilares, congestos, robustos, cilíndricos a angulosos, glabros, eixo de $2^{\mathrm{a}}$ ordem 6-10 mm compr.; bráctea $1^{\text {a }}$ ordem ca. $1 \mathrm{~mm}$ compr., largamente oval, persistente, glabra; bráctea $2^{\mathrm{a}}$ ordem ca. 0,7 $\mathrm{mm}$ compr., oval, persistente; brácteas $3^{\mathrm{a}}$ ordem ca. $0,7 \mathrm{~mm}$ compr., ovais, persistentes; bractéolas $0,4-0,5 \mathrm{~mm}$ compr., ovais, persistentes, opostas, situadas na base do cálice; Flores 15,9-18 mm compr., pétalas violáceas com pontuações juntamente com o cálice; pedicelo 3-4 mm compr., glabro; cálice 3,9-4 × 4,9-5 mm, cupuliforme, truncado, glabro 

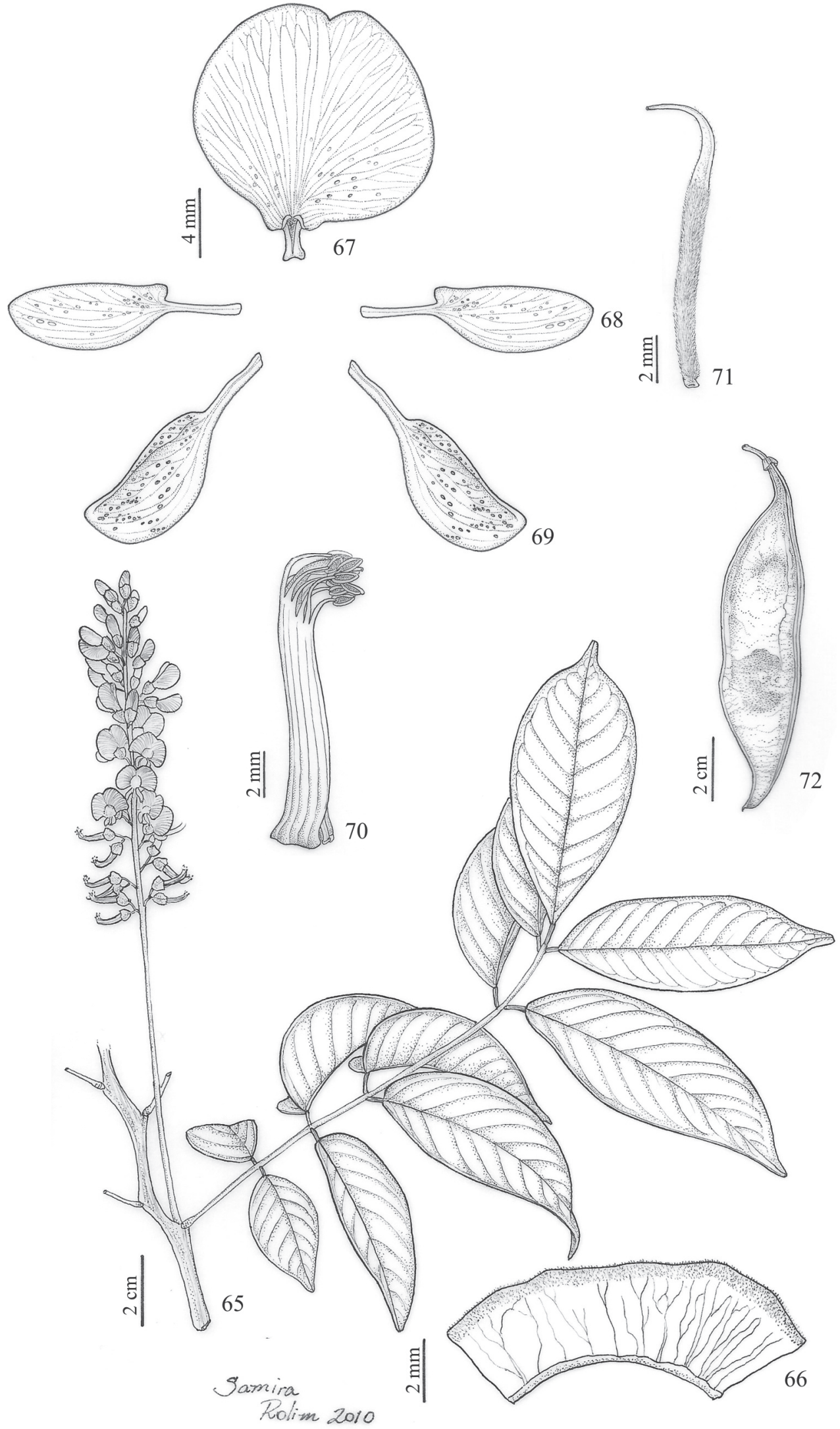

Figuras 65-72. Lonchocarpus violaceus (Jacq.) Kunth ex DC.: 65. Ramo florido; 66. Cálice rebatido; 67. Estandarte; 68. Ala; 69. Pétala da quilha; 70. Androceu; 71. Gineceu; 72. Legume samaroide. (65-71: Hatschbach 60059 - MBM; 71: Raimundo 1127 - CEPEC). 
externamente, com uma faixa de tricomas internamente; estandarte 9-10 $\times$ 9-10 $\mathrm{mm}$, largamente oboval, face interna glabra; face externa indumentada apenas sobre as nervuras, ápice arredondado e ligeiramente emarginado, base largamente obtusa, conspicuamente biapendiculada, unguícula 2,3-2,4 mm compr, carnosa e canaliculada; alas 8,9-9 × 3,7-3,8 mm, oblongo-falcadas, ápice arredondado, base obtusa, margem calosa, serícea externamente sobre as nervuras, unguícula 4,1-4,2 mm compr., ligeiramente curva; pétalas da quilha $8,4-8,5 \times 3,9-4 \mathrm{~mm}$, elíptico-falcada, base obtusa, fortemente umbonada,, unguícula $3,8-4 \mathrm{~mm}$ compr.; tubo estaminal 0,9-0,8 $\times 1,9 \mathrm{~mm}$, glabro, carnoso, bicaloso basalmente, anteras $0,8-9 \mathrm{~mm}$ compr., lanceoloides, ligeiramente apiculadas; ovário 0,9-10 × ca. $1 \mathrm{~mm}$, linear, curtamente seríceo, estipe 1,9-2 mm compr., etilete 3,9-4 mm compr., glabro, óvulos 3-5. Legume samaroide 7,5-19 $\times 2,4-2,5 \mathrm{~cm}$, elípticos, oblongo-elíptico ou elíptico-oboval, cartáceo, glabro, quando maturo verde-claro, base cuneada a atenuada, ápice obtuso a acuminado, margem vexilar alada; estípite 1-1,5 cm compr. Sementes 1 ou 2(3), 1,3-1,4 × 0,8$0,9 \mathrm{~cm}$, reniformes, lisas, castanho-escuras.

Material selecionado: Brasil. Bahia: Almadina, rodovia para Ibitupan, plantação de cacau, 12/III/1971, fr., S.P. Raimundo 1127 (CEPEC, RB). Espírito Santo: Santa Teresa, rio 5 de novembro, propriedade dos Irmãos Ferrari, 16/XI/1988, fl., H.Q.B. Fernandes 2626 (CEPEC, RB); Domingos Martins, Melgaço, Rodovia para Santa Teresa, 8/XI/1993, fl, G. Hatschbach et al. 60059 (K, MBM, UEC).

Material adicional examinado: Colômbia. Guajira: Peninsula, 31/III/1917, fr., M.T. Dawe 544 (K); Magdalena: between Richacha and La Paz, 100 m s.n.m., 27/XI/1943, fl., O. Haught 3893 (K). Dominica. Capucin, 26/VI/1982, S. Barrier 3631 (B, G). Saint Mark: Scott's Head, 20/VI/1965, fl., G.L. Webster 13441 (P); West Indies, Salisbury, Baroui na costa oeste, 18-19/VII/1964, fl., R.L. Wilbu et al. 7645 (P). Martinica. 1871, fr., M. Hahn 576 (P); Caravelle, 20/ VII/1945, fl., H. Stehlé 5993 (P). México. Campeche, región

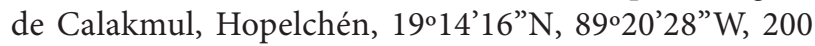
m, 12/I/1999, fr., E. Martínez et al. 31964 (M). Trinidad e Tobago. De la Trinite, 1826, fl., F.W. Sieber 133 (P); Tetron Bay, 6/X/1927, fl., W.E. Broadway 6678 (FHO). Venezuela. Aragua: Caracas, near San Juan de los Morros, 12/IX/1927, fl., H. Pittier 12534 (M); Falcon: Distrito Silva, 1054'N, $68^{\circ} 16^{\prime \prime} \mathrm{W}, 30 / \mathrm{VIII} / 1974$, fl., J.A. Steyermark \& B.J. Manara 110460 (P). El Valle, Island of Margarita, 26/VII/1901, fl., O. Miller \& J.R. Johnston 257 (K, P).

Distribuição e ecologia: espécie com distribuição ampla nas Américas, sendo registrada desde o México até o norte da América do Sul (Colômbia, Venezuela). É citada pela primeira vez para o Brasil, onde cresce nas florestas úmidas no nível do mar e em encosta de morro, sobre solos argilosos dos Estados da Bahia e Espírito Santo. Floresce em novembro e frutifica em março.

Relacionamentos e caracterização: Lonchocarpus violaceus assemelha-se morfologicamente a L. longipedicellatus
Pittier com a qual compartilha os folíolos translúcido-punctados, pseudorracemos com eixos de $2^{\mathrm{a}}$ ordem longos (até $1,1 \mathrm{~cm}$ compr), flores violáceas com pontuações leitosas, cálice cupuliforme e truncado, estandarte com base marcadamente biapendiculada e ovário 3-5-ovulado. No entanto, em L. longipedicellatus, os ramos jovens são pubescentes a vilosos, os folíolos indumentados, oblongos, obtusos na base, os frutos são quilhados na margem superior e o ovário é séssil, enquanto Lonchocarpus violaceus possui ramos e folíolos glabros, sendo os folíolos ovais a oval-elípticos com base usualmente oblíqua, frutos alados na margem superior e o ovário estipitado. Lonchocarpus violaceus distingui-se das demais espécies estudadas pelos folíolos translúcido-punctados com base usualmente oblíqua, cálice truncado, glabro externamente e com uma faixa de tricomas internamente.

Nomenclatura: Pittier (1917) considerou L. violaceus sinônimo de L. punctatus, posição também assumida por Howard (1988) e Aymard et al. (2007). Analisando as coleções-tipo dessas duas espécies, não há dúvidas de que são coespecíficas. No entanto, dada a prioridade de Robinia violacea, $L$. violaceus deve é o nome correto da espécie neste gênero. Dentre os síntipos de Lonchocarpus benthamianus (Duss 1901 e 2663, Hahn 1123, Waby 9 e 106), apenas a coleção Hahn 1123 foi encontrada. Como esse material representa bem a diagnose da espécie, ele foi designado seu lectótipo.

\section{Agradecimentos}

Aos curadores dos herbários citados pelo empréstimo de suas coleções, ao CNPq pela bolsa de Pós-Doutorado (processo 150903/2010-3) concebida ao primeiro autor, a FAPESP pelo apoio financeiro (processo 2008/57095-5), ao Programa de Pós-graduação em Biologia Vegetal do Instituto de Biologia da Universidade Estadual de Campinas pelas facilidades concedidas, a Profa. Dra. Sandra Maria Carmelo Guerreiro pelo apoio concernente à bolsa de pós-doutorado, a Sra. Samira Rolim pelas ilustrações e aos assessores anônimos pelas contribuições ao artigo.

\section{Referências Bibliográficas}

Aublet, J.B.C.F. 1775. Histoire des plantes de la Guiane Françoise. v. 2. Paris, Pierre François Didot jeune.

Aymard, G.A.; Barneby R.C.; Berry P.E.; Cowan R.S.; Silva, M.F.; Kearns, D.M.; Sprada Tavares, A.; Stergios, B.; Velázquez, D.; Wunderlin, R.P.; Xena, N. \& Zarucchi J.L. 2007. Leguminosae-Faboideae. In: Funk, V.; Hollowell, T.; Berry, P.; Kelloff C. \& Alexander S.N., Checklist of the Plants of the Guiana Shield (Venezuela: Amazonas, Bolivar, Delta Amacuro; Guyana, Surinam, French Guiana). Contributions from the United States national Herbarium 55: 1-584.

Bentham, G. 1860. Synopsis of Dalbergieae, a tribe of Leguminosae. Journal of the Linnean Society 4. suppl.: 1-128.

Bentham, G. 1862. Leguminosae. Pp. 277-286. In: Martius, C.F.P.; Eichler, A.W. \& Urban, I. (Eds.). Flora brasiliensis. v. 15. Lipsiae, F. Fleischer. 
Brummit, R.K. \& Powell, C.E. 1992. Authors of plant names. Kew, Royal Botanic Gardens.

Geesink, R. 1984. Scala Milletiearum. A survey of the genera of the tribe Millettieae (Leguminosae - Papilionoideae). Leiden Botanical Series. 8. Leiden, Brill E.J. \& Leiden University Press.

Hickey, L.S. 1973. Classification of the architecture of dicotyledonous leaves. American Journal of Botany 60: 17-33.

Howard, R.A. 1988. Leguminosae. Pp. 334-538. In: Flora of the Lesser Antilles: Leeward and Windward Islands. (Dicotyledoneae- Part 1). v. 4. Harvard, Arnold Arboretum.

Hu, J.M.; Lavin, M.; Wojciechowski, M.F. \& Sanderson, M.J. 2002. Phylogenetic analysis of nuclear ribosomal ITS $/ 5.8 \mathrm{~S}$ sequences in the tribe Millettieae (Fabaceae): Poecilanthe-Cyclolobium, the core Millettieae, and the Callerya group. Systematic Botany 27: 722-733.

Kleinhoont, A. 1933. Novitates taxonomicae I. Recueil des Travaux Botaniques Neerlandais 30: 163-184.

Lawrance, G.H.M.; Buchheim, A.F.G.; Daniels, G.S \& Dolezal, H. 1968. Botanico-Periodicum- Huntianum. Pittsburg, Hunt Botanical Library.

Lewis, G.P. 1987. Legumes of Bahia. Kew, Royal Botanic Gardens.

Lima, H.C. 1995. Leguminosas da Flora Fluminensis - J.M.da C. Vellozo, Lista atualizada das espécies árboreas. Acta Botanica Brasilica 9: 123-146.

McNeill, J.; Barrie, F.R.; Burdet, H.M.; Demoulin, V.; Hawksworth, D.; Marhold, K.; Nicolson, D.H.; Prado, J.; Silva, P.C.; Skog, J.E.; Wiersema, J.E.H. \& Turland, N.J. 2006. International Code of Botanical Nomenclature (Vienna Code) adopted by the Seventeenth International Botanical Congress Vienna, Austria, July 2005. [Regnum Vegetabile. V. 146.] Ruggell, A.R.G. Gantner Verlag.

Neubert, E.E. \& Miotto, S.T.S. 1996. O gênero Lonchocarpus Kunth (Leguminosae-Faboideae) no Rio Grande do Sul. Iheringia, Série Botânica 47: 73-102.

Pittier, H. 1917. The Middle American species of Lonchocarpus. Contributions from the United States National Herbarium 20: 37-93.

Pittier, H. 1928. Contribuciones a la dendrología de Venezuela. Árboles y arbustos del orden de las Leguminosas. III-Papilionáceas. Trabajos del Museo Comercial de Venezuela 4: 179-259.

Radford, A.E.; Dickson, W.C.; Massey, J.R. \& Bell, C.R. 1974. Vascular plant systematics. New York, Harper \& Row.

Schrire, B.D. 2005. Tribe Millettieae. Pp. 367-387. In: Lewis, G.P., Scrhire, B.; Mackinder, B. \& Lock, M. 2005. Legumes of the world. Kew, Royal Botanic Garden.

Schrire, B.; Lavin, M. \& Lewis, G.P. 2005. Global distribution patterns of the Leguminosae: insights from recent phylogenies. In: Friis, I. \& Balslev, H. (Eds.). Plant diversity and complexity patterns: local, regional and global dimensions. Biologiske Skrifter 55: 375-422.

Silva, M.J. 2010. Filogenia e biogeografia de Lonchocarpus s.l. e revisão taxonômica dos gêneros Dahlstedtia Malme e Muellera L.f. (Leguminosae, Papilionoideae, Millettieae). Tese de Doutorado. Universidade Estadual de Campinas, Campinas. http://www.bibliotecadigital. unicamp.br/document $/$ ?code $=000770260$

Silva, R.R. \& Tozzi, A.M.G.A. 2008. A new species of Lonchocarpus (Leguminosae, Papilionoideae) from Mato Grosso do Sul, Brazil. Brittonia 60: 34-37.

Silva, M.J. \& Tozzi, A.M.G.A. 2010. Lonchocarpus. In Lista de espécies da Flora do Brasil. Rio de Janeiro, Jardim Botânico do Rio de Janeiro. (http://floradobrasil.jbrj.gov.br/2010/FB022921).

Silva, M.J.; Tozzi, A.M.G.A. \& Lewis, G.P. 2010. Two new species of Lonchocarpus (Leguminosae, Papilionoideae, Millettieae) from Brazil. Kew Bulletin 65: 29-35.

Sousa, M. 1990. Adiciones a las Papilionadas de la flora de Nicaragua y una nueva combinación para Oaxaca, México. Annals of the Missouri Botanical Garden 77: 573-577.

Sousa, M. 1992. Willardia una nueva sección del género Lonchocarpus (Leguminosae). Anales Instituto Biologia da Universidade Nacional do México, Serie Botanica 63: 147-154.

Sousa, M. 2005a. Las especies del género Lonchocarpus sect. Lonchocarpus (Leguminosae, Papilionoideae: Millettieae) para a Bolivia. Novon 15: $590-598$
Sousa, M. 2005b. Especies nuevas de Lonchocarpus (Millettieae: Leguminosae) para Costa Rica y Panamá; lectotipificación de la sect. Densiflori Benth. Revista Mexicana de Biodiversidad 76: 119-127.

Sousa, M. 2009a. La sect. Punctati del género Lonchocarpus (Leguminosae, Papilionoideae, Millettieae) para Mesoamérica. Novon 19: 239-255.

Sousa, M. 2009b. Standleyi una nueva sección del género Lonchocarpus (Leguminosae), nuevas especies y subespecies para Mesoámerica e Sudamérica. Acta Botanica Mexicana 86: 39-69.

Sousa, M. 2009c. La sect. Obtusifolii del género Lonchocarpus (Leguminosae, Papilionoideae, Millettieae) para Mesoamérica. Novon 19 520-533.

Stafleu, F. A. \& Cowan, R.S. 1976-1988. Taxonomic literature. Utrech, Bohn, Scheltema \& Holkema.

Teixeira, S.P.; Castro, M.M. \& Tozzi, A.M.G.A. 2000. Secretory cavities and pellucid dots in leaflets of Lonchocarpus (Leguminosae, Papilionoideae, Millettieae). Plant Systematics and Evolution 221: 61-68.

Thiers, B. 2009. [continuously updated]. Index Herbariorum: A global directory of public herbaria and associated staff. New York Botanical Garden's Virtual Herbarium. http://sweetgum.nybg.org/ih/. (Acesso em 4/2011).

Tozzi, A.M.G.A. 1989. Estudos taxonômicos dos gêneros Lonchocarpus Kunth e Deguelia Aubl. no Brasil. Tese de Doutorado. Universidade Estadual de Campinas, Campinas. http://cutter.unicamp.br/ document/?code $=$ vtls 000056059

Tozzi, A.M.G.A. 1995. New species of Lonchocarpus Kunth (Leguminosae - Papilionoideae - Millettieae) from Brazil. Kew Bulletin 50: 173-177.

Tozzi, A.M.G.A. \& Silva, M.J. 2007. Sinonimizações em Lonchocarpus Kunth (Leguminosae - Papilionoideae - Millettieae). Rodriguésia 58: $275-282$

Tulasne, L.R. 1843. Nova quaedum proponit genera in Leguminosarum classe. Annales des Sciences Naturelles: Botanique, ser. 2, 20: 136-138.

Zamora, N.A. 2011. El caso de Lonchocarpus costaricensis (Leguminosae, Papilionoideae), una especie endêmica de Costa Rica: un complejo taxonómico-nomenclatural, y una nueva espécie. Anales del Jardín Botánico de Madrid 68: 7-14

\section{Apêndice 1 - Lista de exsicatas}

Abbott, J.R. 16330 (6); Adams, C.D. 7308 (3); Aguiar, A.C. 221 (1); Aguiar, O.T. 151 (6); Alfred, B. 426 (5); Allemão 430 (7); Almeida J. 215 (1); Amorim, A.M. 2101 (1); Amshoff, G.J.H. 5567 (7); Andrade-Lima, D. 49-151 (7); Appun, C.F. 746 (3); Arbo, M.M. 7288 (7); Árbocz, G.F. 9855 (6); Archer, W.A. 2564, 2588 (7); Aristeguieta, L. 4161, 7041 (4); Atkins, S. 688 (3); Aublet, J.B.C.F. s.n. (3); Baker, J.G. 5263 (7); Barreto, M. 5784, 5801, 10411, 10595 (1); Barrier, S. 3631, 3688 (9); Beauvois, P. s.n. (7); Becket, J.E. 8533 (3); Bello, D.E. s.n. (7); Belém 2959 (1), 3277 (7); 3388 (1); Berghen, V.C. 9539 (7); Bernardi, A.L. 1171 (4), 2883 (7), 7407 (2), 7409 (4); Black, G.A. 51-13260 (4); Blanchet, J.S. 323, 3213, 3254 (1); Bobskeherr 181 (2); Bonpland, A. 1571 (7); Bowie, J. 2078 (1); Breteller, F.J. 5156 (3), 7296 (7); Bridarolli 3622 (5); Broadway, W.E. 2275 (3); Burchell, W.J. 2716 (1); Cabrera, A.L. 13650 (5); Cárdenas, L. 4137 (2); Cardona, F. 2132 (2); Carvalho, A.M. 543 (1); Catharino, E.L.M. 621 (1); Cervi, A. 7339 (1); Chagas e Silva, F. 1484 (1); Chung, F. 233 (1); Cid, C.A.F. 9955 (1); Claussen, P. 30, 61, 160, 184, 219, 235, 606a, 870, 892, 1718, s.n. (1); Clos 2115 (5); Collares, J.E.R. 192 (7); Cuatrecasas, J. 7567 (7), 8676 (1), 20000 (3); Cunha, C.N.D.A. 2077 (7); Curtis, A.H. 462 (3); Dalembert, B. 1820, 1821 (9); Damasceno, J. 3263 (6); Damião, C. 2868 (8); Davidse, G. 19486 (4), 35666 (3); Dawe, M.T. 544 (9); Daza, A. 16500 (2); D’Orbigny s.n. (4); Duarte, A.P. 753 (1), 4645 (1), 8603 (1), 8675 (1); Ducke, A. 551 (8), 1393 (4), 1514 (8), 15250 (2), 17006 (2), 18208 (3), 23310, 24309, 24310 (8), s.n. (2); Durity, F.R. 12632 (7); Dusén, P. 17475 (1); Duss 681 
(3); Eggers, H. 743, 948 (3), 1182 (7); 4964 (3), 15766 (5); Eiten, G. 10495 (7), 4761 (7); Emelen, V. 127 (1), Emmerich, K. 3006 (1); Ern, H. 2476, 2485 (7); Fendler, A. 318 (7), 1861 (4); Fernandes, H.Q.B. 2626 (9); Ferreira, J.D.C.A. 109 (7); Fiebrig, K. 4389 (6); Flores, A. 1446 (1); Focke, H. 895 (2); Foster, R.B. 3292, 8335 (8), Fróes, R.L. 23811 (8), 23082 (4), 23577, 27002, 30312, 30396 (7); Fuchs, H.P. 22358 (3); Fuertes 63 (7); Galeotti 12 (9); Gardner, G. 1275 (7); Gaudichaud, C. 232 (7); Gentry, A. 8613 (3); Gibbs, P. 4344 (1); Geerling C. 348 (7); Gillespie, L.G. 1176 (3); Glaziou, A. 1029, 6867 (1), 10552 (7), 12600,13700, 13720, 14612 (1); Guedes, L. 1008, 1072 (1); Guedes, M. s.n. (3); Guedes, R. 2287 (1); Guillemin, M. 241 (1); Haber, E. s.n. (7); Hage, J.L. 367, 1547 (1); Hahn, M. 576, 1123 (9), 1504 (3); Hakki, M. 723 (7); Harris 10812 (3); Hart, J.H. 1888 (3), 3873, (7); Hassler, E. 706 (5); Hatschbach, G. 3512, 3371 (1), 13375 (5), 18059, 18162, 25963, 25965, 28543, 37891 (1), 37789 (7), 37929 (5), 39121 (7), 41832, 41869 (1), 56048 (7), 56411 (5), 60059 (9), 60390 (7), 60943 (6), 69245, 71317 (1), 73927 (6); Harley, R.M. 2744 (1), 16291 (7); Haught, O. 4538 (3), 3893 (9); Herter, W. 1848 (5), Henkel, T.W. 2967 (3); Hennis, W. 486 (4); Henry, B. 15 (9); Heringer, E.P. 91, 92 (1), 536 (7); 799, 2211, 5726 (1); Hermann, V. 719 (7); Holton, P.G. 990, 875 (7); Hostmann, W.R. 234 (2); Humboldt, A. 1127 (9); Huges-Jones, D.L. 354 (7); Hughes, C.E. 774 (9), Huidobro, A.M.R. 4393 (5); Irwin, H.S. 27365 (1); Jack, J.G. 6017 (3); Jasen-Jacobs, M.J. 461 (2); Johnston J.R. 22 (9), 23 (4); Jesus, J.A. 617 (1); Killip, E.P. 30566 (3); Kinupp, V.F. 980 (5); Klein, R. 274, 963, 1224, 8086 (1); Klitgaard, B.B. 41 (1), 48 (1); Klug, G. 2930, 2991, 3967 (8); Krukoff, B.A. 4903 (8), 10028 (2); Kuhlmann, J.G. 164 (1), 6678 (7), 1273, 18208 (8); Langsdorff, G.H. 2476 (1); La Sagra, R. 141 (7); Ledru, M. (3); Leitão-Filho, H.F. 1301 (1), 12216 (6), 12263, 22909, 34749 (1); Leoni, L.S. 538 (1); Lerouzey 12468 (7); Lewis, G.P. 1110, 1114 (7); Lidden 513 (3); Liesner, R. 439, 2185 (3), 11208, 11230 (4); Lillo, M. 11017 (5); Lima, H. C. 2658, 3044, 6227 (1); Linden, M. 275 (9), 1984 (7); Llamas, F. 706 (5); Lorentz, P. 888 (5); Marshall, R.C. 12669 (3); Martín-Ballesteros 800 (3); Martínez, E. 31964 (9); Martius, C.F.P. 13831-13837 (8); Mathes L. 10071 (3); Mattos, L.A.F. 9788 (1); Maruñak, V. 59 (5); Matos Silva, L.A. 2680 (1); Medeiros, D.A. 7 (1); Melinon 373 (3); Mello-Filho, L.E. 2654 (3); Menezes, E. 458 (6); Mexia, Y. 6452a (8); Milliken, W. 449 (4), 450 (7); Mori, S.A. 9634 (7); Nee, M. 11020 (3), 37932, 41811, 40038, 41639, 41811, 45028 (6); Nelly, D. 8924 (1); Oldeman, R.A.A. 548 (7); 1023 (2), 14441 (3); Oliveira, E. 3457 (8), 3459 (3); Ortega, L.C.S. 2285 (5), 5776 (7); Pabst, G. 9262 (1);
Pagano 352 (1); Pater, C.V.O.S.B. 624 (2); Palmer, E. 598 (7); Paul, H.A. 6023 (3); Paula-Souza, J. 4630 (7); Pavón 1827 (7); Pedersen, T.M. 8144 (5); Pennington, T.D. 10780 (1), 16750 (2), 17120 (8), 17204 (1); Pereira, B.A.S. 2964 (6); Perrotet 1825 (9); Pessoa, S.V.A. 692 (1); Pinheiro 1050 , 1731 (1); Pipoly, J.J. 11681 (3); Pires, J.M. 1394, 11266 (3), 2653 (7), 4517 (8), 14661 (4); Pittier, H. 14880 (2); Pivetta (5); Plée, A. 977 (3); Poeppig, E.F. 2341 (8); Poiteau, P.A. s.n. (3); Pott, A. 4649 (7); Prance, G.T. 1316 (7), 24502, 24651 (8); Prevost, M.F. 1012 (2); Proctor, J.C. 227, 28839, 35350, 36295 (3); Queiroz, L.P. 2975, 10714 (1); Quentin, R.P. 184 (9); Raimundo, S.P. 1127 (9), Rambo 1386, 39979 (5); Ratter, J.A. 5867 (4), 6014 (6); Regnell, A.F. 465 (1); Reitz, R. 2347, 4153 (1), 4714 (5), 5905, 6074, 6651, 9043 (1); Rico, L. 1349 (6); Riedel, L. 494, 689, 2358 (1); Rios, J. 1820 (8); Rodriguez, L. 4029 (9), 12330 (5); Rodrigues, I.A. 688 (4); Romão, G.O. 1086 (1); Rugel, F. 223 (7); Rusby, H. H. 1329 (2); Sáer, J. 648 (9); Sagot, P.A. 125 (3); Sampaio, D. 169 (5); Sandermann, C. 6110 (7); Santos, A.P.M. 330 (1); Santos, T.S. 1550 (1); Sastre, C. 7029 (3), 7868 (9); Schäfer 8558 (7); Schatz, G. E. 874 (7); Schinini, A. 6048, 16768, 17018 (5); Schmidt, F. 169 (2); Schomburgk, R.H. 1841 (3); Schunke, J. 2117, 2579 (8); Seemam 1685 (3), 3540 (5); Sellow, F. 1059 (5); Sehnem, A. 2442, 2443, 3540 (5); Sieber 108 (7), 176 (3); Silva, A.G. 227 (1); Silva, A.M. 46 (1); Silva, J.M. 2863, 3234 (1); Silva, M.J. (1); Silva, N.T. 3366 (1), Silva, R.R. 662 (6); Sintenis 6671 (3); Smith, A.C. 3225 (4); Smith, D.N. 13828 (1); Smith, H. 933, 934 (3); Smith, L.B. 14945 (5); Sousa, M. 3429 (3), 13383, 13385 (1); Souza, V. 147, 273, 279, 350 (7); Sotelo, J.B. 10020 (5); Spada, J. 9, 179, 182 (1); Splitgerber, U. 285 (2); Spruce, R. 4597 (2); Stahl, A. 48 (3); Stehlé, H. 1147 (3), 5993 (9); Steinbach, J. 6719, 7119, 7300 (6), 7902 (2); Stevenson, N.S. 166 (3); Steyermark, J. 86623, 87791 (7); 110476 (9); Sucre, D. 9339 (7); Swartz, O. s.n. (3); Tamashiro, J.Y. 791, 1249 (1); Tessmann, G. 5526, 5027 (8), Thomas, D.W. 2350 (7); Tsuji, R. 1542 (6); Turckhein 2819 (7); Turpin, P. s.n. (7); Tutin, T.G. 107, 217 (3); Ule, E. 5446 (1), 8167 (4); Urban, I. 4991 (7); Urbanetz, C. 52 (1); L. Uribe 658 (7); Vahls, M. s.n. (7);Vargas, E. 4048 (6); Vecchi, O. 174 (1); Vellásquez, R. 21339 (8), Velloso, H.P. 272, 848 (1); Waby, J.T. 8356 (3); Warming, E. 2811 (1); Wasum, R. 11241 (5); Webster, G.L. 13441 (9); White, O.E. 1302 (6); Whitford, H.N. 1075 (3); Wilbur, R.L. 649a (7), 7645 (9); Wilde, E. 36 (1); Wilhens, A.F. 11131 (4); Willdenow, C.L. 13088 (3) Wilson, W.M. 1014 (7); Wood, J.R.I. 15157, 20078, 23873 (6); Wurdack, J.J. 4375, 42843 (2). 